ARTICLE

DOI: $10.1038 / s 41467-018-03235-7$

\title{
Single rhodium atoms anchored in micropores for efficient transformation of methane under mild conditions
}

Yu Tang (1) ', Yuting Li1, Victor Fung ${ }^{2}$, De-en Jiang (1) 2, Weixin Huang 1,3, Shiran Zhang1,3, Yasuhiro Iwasawa4, Tomohiro Sakata4, Luan Nguyen 1,3, Xiaoyan Zhang ${ }^{1,5}$, Anatoly I. Frenkel ${ }^{6,7}$ \& Franklin (Feng) Tao (D) 1,3

Catalytic transformation of $\mathrm{CH}_{4}$ under a mild condition is significant for efficient utilization of shale gas under the circumstance of switching raw materials of chemical industries to shale gas. Here, we report the transformation of $\mathrm{CH}_{4}$ to acetic acid and methanol through coupling of $\mathrm{CH}_{4}, \mathrm{CO}$ and $\mathrm{O}_{2}$ on single-site $\mathrm{Rh}_{1} \mathrm{O}_{5}$ anchored in microporous aluminosilicates in solution at $\leq 150^{\circ} \mathrm{C}$. The activity of these singly dispersed precious metal sites for production of organic oxygenates can reach about 0.10 acetic acid molecules on a $\mathrm{Rh}_{1} \mathrm{O}_{5}$ site per second at $150{ }^{\circ} \mathrm{C}$ with a selectivity of $\sim 70 \%$ for production of acetic acid. It is higher than the activity of free $\mathrm{Rh}$ cations by $>1000$ times. Computational studies suggest that the first $\mathrm{C}-\mathrm{H}$ bond of $\mathrm{CH}_{4}$ is activated by $\mathrm{Rh}_{1} \mathrm{O}_{5}$ anchored on the wall of micropores of $\mathrm{ZSM}-5$; the formed $\mathrm{CH}_{3}$ then couples with $\mathrm{CO}$ and $\mathrm{OH}$, to produce acetic acid over a low activation barrier.

\footnotetext{
${ }^{1}$ Department of Chemical and Petroleum Engineering and Department of Chemistry, University of Kansas, Lawrence, KS 66045, USA. ${ }^{2}$ Department of Chemistry, University of California, Riverside, CA 92521, USA. ${ }^{3}$ Department of Chemistry and Biochemistry, University of Notre Dame, Notre Dame, IN 46556, USA. ${ }^{4}$ Innovation Research Center for Fuel Cells and Graduate School of Informatics and Engineering, The University of Electro-Communications, Chofu, Tokyo 182-8585, Japan. ${ }^{5}$ State Key Laboratory of Photocatalysis on Energy and Environment and College of Chemistry, Fuzhou University, Fuzhou 350116, China. ${ }^{6}$ Department of Materials Science and Chemical Engineering, Stony Brook University, Stony Brook, NY 11794, USA. ${ }^{7}$ Division of Chemistry, Brookhaven National Laboratory, Upton, NY 11973, USA. Correspondence and requests for materials should be addressed to

F.T. (email: franklin.feng.tao@ku.edu)
} 
C $\mathrm{H}_{4}$ has been one of the inexpensive energy resources since the maturation of hydraulic fracturing technology. So far, most processes of transformation of $\mathrm{CH}_{4}$ to intermediate compounds for chemical industries including steam or dry reforming, partial oxidation, and oxidative coupling are performed at high temperatures. One side effect of these processes is the deactivation of catalysts due to coke formation ${ }^{1,2}$. Another is the input of huge amount of energy since they are performed at high temperatures. Thus, activation of $\mathrm{C}-\mathrm{H}$ of $\mathrm{CH}_{4}$ at a low temperature is necessary in order to transform shale gas to intermediate compounds of chemical industries in an energyefficient manner ${ }^{3-9}$.

Acetic acid is one of the important intermediates of chemical industries. The global demand is 6.5 million metric tons per year (Mt/a). Currently, it is produced from methanol carbonylation, in which $\mathrm{CO}$ reacts with methanol to form acetic acid. However, methanol is synthesized from $\mathrm{CO}$ and $\mathrm{H}_{2}$, which are produced from steam reforming processes of either methane or coal at high temperatures ${ }^{10}$. Replacement of the current high-temperature catalysis toward production of acetic acid with catalysis at low temperatures would be feasible if a catalytic process on a heterogeneous catalyst could efficiently, directly transform $\mathrm{CH}_{4}$ to acetic acid under a mild condition. Transformations of methane to methanol and acetic acid on isolated palladium and rhodium atoms anchored in zeolite in liquid solution were simultaneously explored in our group since early 2012 . We reported oxidation of methane to form methanol on $\mathrm{Pd}_{1} \mathrm{O}_{4}$ anchored in ZSM-5 in aqueous solution at low temperature in $2016^{11}$. Other than the mild oxidation of $\mathrm{CH}_{4}$ to $\mathrm{CH}_{3} \mathrm{OH}$ with supported isolated $\mathrm{Pd}$ atoms anchored in ZSM-5, we have simultaneously studied oxidization of methane through coupling with $\mathrm{CO}$ and $\mathrm{O}_{2}$ to methanol and acetic acid on isolated $\mathrm{Rh}$ atom anchored in ZSM-5 since 2012 and the $\mathrm{Rh}_{1} \mathrm{O}_{5} / \mathrm{ZSM}-5$ catalyst was synthesized and its high activity was confirmed and its structure was identified before summer of 2014.

Formation of single sites is a significant approach to developing catalyst toward high catalytic activity and selectivity ${ }^{11-17}$. Separately anchoring catalytic sites $\left(M_{1}\right)$ on an oxide support $\left(M_{1} /\right.$ $\mathrm{A}_{\mathrm{x}} \mathrm{O}_{\mathrm{y}}$ ) tunes the electronic state of catalytic sites of metal atoms $\left(\mathrm{M}_{1}\right)$, which are typically continuously packed on surface of a metal nanoparticle or periodically located in a surface lattice of a metal oxide nanoparticle $\left(\mathrm{M}_{\mathrm{x}} \mathrm{O}_{\mathrm{y}}\right)$. Compared to continuously packed $\mathrm{M}$ atoms on surface of a metal nanoparticle (....M-M$\mathrm{M}$....) and periodically packed $\mathrm{M}$ cations in surface lattice of a metal oxide nanoparticle $\left(\cdots \mathrm{O}-\mathrm{M}_{1}-\mathrm{O}-\mathrm{M}_{1}{ }^{*}-\mathrm{O}-\mathrm{M}_{1}-\mathrm{O}-\mathrm{M}_{1}-\mathrm{O} \quad \cdots \cdot\right)$, these isolated cation sites $\left(\mathrm{M}^{*}\right)$ anchored on surface of a substrate oxide $\left(\mathrm{A}_{\mathrm{a}} \mathrm{O}_{\mathrm{b}}\right), \cdots \mathrm{O}-\mathrm{A}-\mathrm{O}-\mathrm{M}_{1}{ }^{*}-\mathrm{O}-\mathrm{A}-\mathrm{O}-\mathrm{A}$, exhibit a distinctly different coordination of $M$ atoms. Thus, those isolated cations $\left(M_{1}\right)$ could exhibit a catalytic performance distinctly different from a metal oxide nanoparticle $\left(\mathrm{M}_{\mathrm{x}} \mathrm{O}_{\mathrm{y}}\right)$ or a metal nanoparticle.

We separately anchored Rh cations on the internal surface of micropores of an aluminosilicate, H-ZSM-5 through ion exchange between $\mathrm{Rh}^{3+}$ in solution and $\mathrm{H}^{+}$on the internal surface of micropore, similar to the isolated palladium atoms in ZSM-5 ${ }^{11}$. As these Bronsted sites are typically isolated, $\mathrm{Rh}^{3+}$ cations can be separately anchored on Bronsted sites. Production of acetic acid through coupling $\mathrm{CH}_{4}$ with $\mathrm{CO}$ and $\mathrm{O}_{2}$ $\left(2 \mathrm{CH}_{4}+2 \mathrm{CO}+\mathrm{O}_{2} \rightarrow 2 \mathrm{CH}_{3} \mathrm{COOH}\right)$ is efficiently catalyzed by these singly dispersed $\mathrm{Rh}$ sites, $\mathrm{Rh}_{1} \mathrm{O}_{5}$. Different from rhodium atoms anchored on nonporous silicate and other nonporous oxide, this heterogeneous catalyst exhibits high activity in transforming $\mathrm{CH}_{4}$ to acetic acid, about $0.1 \mathrm{CH}_{3} \mathrm{COOH}$ molecules per $\mathrm{Rh}$ site per second with a selectivity of $\sim 70 \%$ for production of acetic acid. Isotope-labeled experiments using ${ }^{13} \mathrm{CH}_{4}$ and ${ }^{13} \mathrm{CO}$ show that $\mathrm{CH}_{3}$ of $\mathrm{CH}_{3} \mathrm{COOH}$ forms from activation of $\mathrm{CH}_{4}$ to $\mathrm{CH}_{3}$ and $\mathrm{C}=\mathrm{O}$ of $\mathrm{CH}_{3} \mathrm{COOH}$ from insertion $\mathrm{CO}$ to $\mathrm{Rh}-\mathrm{OH}$. Density functional theory (DFT) calculation suggests that activation of $\mathrm{C}-\mathrm{H}$ of $\mathrm{CH}_{4}$ and $\mathrm{O}-\mathrm{O}$ of $\mathrm{O}_{2}$ are performed on a $\mathrm{Rh}_{1}$ atom and thus $\mathrm{CH}_{3}$ - and $\mathrm{HO}$ are formed on the $\mathrm{Rh}_{1}$ atom. Insertion of $\mathrm{C}^{\prime} \mathrm{O}^{\prime}$ to $\mathrm{Rh}_{1}-\mathrm{O}$ bond of $-\mathrm{Rh}_{1}-\mathrm{OH}$ to form a $-\mathrm{Rh}_{1}-\mathrm{C}^{\prime} \mathrm{O}^{\prime} \mathrm{OH}$ on $\mathrm{Rh}_{1}$ atom; the formed $-\mathrm{Rh}_{1}-\mathrm{C}^{\prime} \mathrm{O}^{\prime} \mathrm{OH}$ couples with $\mathrm{CH}_{3}$ adsorbed on the same $\mathrm{Rh}_{1}$ atom, generating the first product molecule, $\mathrm{CH}_{3} \mathrm{C}^{\prime}$ $\mathrm{O}^{\prime} \mathrm{OH}$. The left $-\mathrm{Rh}_{1}=\mathrm{O}$ activates the second $\mathrm{CH}_{4}$ to form $\mathrm{CH}_{3}$ and $\mathrm{HO}$; the formed $\mathrm{CH}_{3}$ couples with $\mathrm{CO}$ to form acetyl, which couples with adsorbed $\mathrm{HO}$ to form the second acetic acid molecule.

\section{Results}

Preparation of isolated $\mathrm{Rh}$ catalytic site in ZSM-5. Rh cations were introduced to the internal surface of micropores of ZSM-5 through a method integrating vacuum pumping and incipient wetness impregnation (IWI). To minimize the amount of $\mathrm{Rh}$ cations to be deposited on external surface of a ZSM-5 particle, solution of $\mathrm{Rh}^{3+}$ with the same volume as the pore volume of ZSM-5 was slowly dropped to ZSM-5 powder with a syringe pump when the catalyst powder was continuously stirred and remained in vacuum. During IWI, Rh cations exchanged with singly dispersed Brønsted acid sites of $\mathrm{H}-\mathrm{ZSM}-5$, which was prepared through calcining $\mathrm{NH}_{4}-\mathrm{ZSM}-5$ at $400^{\circ} \mathrm{C}$ for $12 \mathrm{~h}$. After the introduction of $\mathrm{Rh}^{3+}$, the samples were further dried in an oven at $80^{\circ} \mathrm{C}$ for $3 \mathrm{~h}$ and calcined in air at $550{ }^{\circ} \mathrm{C}$ for $3 \mathrm{~h}$, forming the catalyst, $\mathrm{Rh} / \mathrm{ZSM}-5$. The evolution of the chemical environment of Rh cations in ZSM-5 was shown in Supplementary Fig. 1. The concentration of Rh cations in the as-synthesized catalyst was measured through inductively coupled plasma atomic emission spectroscopy (ICP-AES). Before an ICP-AES measurement, 28 $\mathrm{mg}$ of $0.10 \mathrm{wt} \% \mathrm{Rh} / \mathrm{ZSM}-5$ was dissolved in aqua regia. For catalyst with a nominal mass ratio of $\mathrm{Rh}$ to aliminosilicate, $0.10 \mathrm{wt} \%$, the measured weight percent was $0.10 \mathrm{wt} \%$, which suggests no obvious loss of $\mathrm{Rh}$ atoms during the preparation. X-ray photoelectron spectroscopy (XPS) studies of the as-synthesized $0.10 \mathrm{wt}$ $\% \mathrm{Rh} / \mathrm{ZSM}-5$ show the lack of $\mathrm{Rh}$ atoms in surface region of catalyst particles (red spectrum in Fig. 1c). The lack of Rh atoms in surface region revealed with XPS together with the $0.10 \mathrm{wt} \% \mathrm{Rh}$ in the as-synthesized catalyst measured with ICP-AES suggests that these introduced $\mathrm{Rh}$ atoms were anchored in micropores of ZSM-5 particles instead of the external surface of ZSM-5 particles. At a high loading $(0.50 \mathrm{wt} \% \mathrm{Rh} / \mathrm{ZSM}-5)$, unfortunately rhodium oxide nanoparticles $(2-4 \mathrm{~nm})$ were formed as evidenced by the low contrast patches in transmission electron microscopy (TEM) image (Fig. 1b), consistent with the observed Rh 3d photoemission feature in studies of sample using XPS (black spectrum in Fig. 1c) ${ }^{18}$.

The existence of $\mathrm{Rh}$ atoms in the microproes of ZSM-5 after catalysis was confirmed by the measured concentration of $\mathrm{Rh}$ atoms remained in micropores with ICP-AES, which was $0.098 \%$. Extended X-ray absorption fine structure spectroscopy (EXAFS) was used to characterize the chemical environment of anchored $\mathrm{Rh}$ atoms of used $0.10 \mathrm{wt} \% \mathrm{Rh} / \mathrm{ZSM}-5$ (the catalyst after reaction). After catalysis, the used catalyst powder was centrifuged and thus washed with deionized $\mathrm{H}_{2} \mathrm{O}$ several times and then dried in oven at $200{ }^{\circ} \mathrm{C}$. The obtained powder was used for EXAFS studies in flowing $\mathrm{He}$ at $150^{\circ} \mathrm{C}$. r-space spectrum of K-edge of $\mathrm{Rh}$ atoms of the used catalyst show that $\mathrm{Rh}$ atoms bond with oxygen atoms and the average coordination number of oxygen atoms to a $\mathrm{Rh}$ atom is $\mathrm{CN}(\mathrm{Rh}-\mathrm{O})$ of $5.23 \pm 0.52$ (Fig. 1e, f). Notably, no contribution of Rh-Rh metal bonds was needed to fit the r-space spectrum of Rh K-edge (Fig. 1e), suggesting that there is no evidence for formation of Rh-Rh metal bonds. This is consistent with the oxidization state of $\mathrm{Rh}$ shown in Fig. 1h. Similar to literature ${ }^{19-21}$, the second shell of rhodium oxide at $2.60 \AA$ in $r$ - 
a

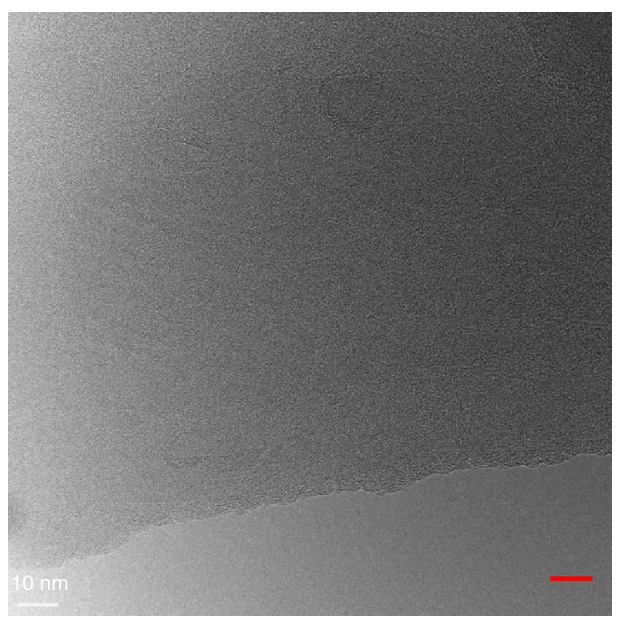

C

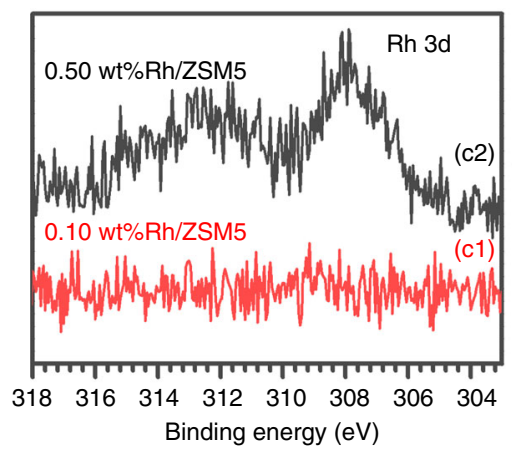

e

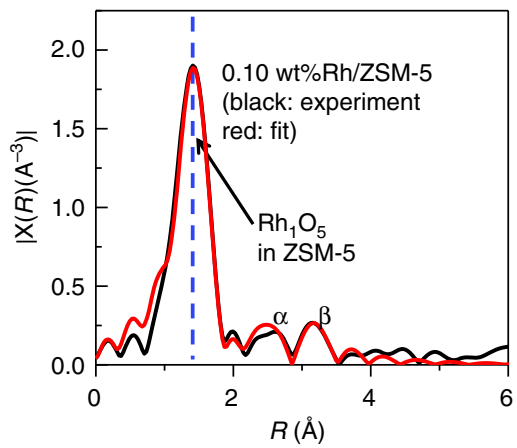

g

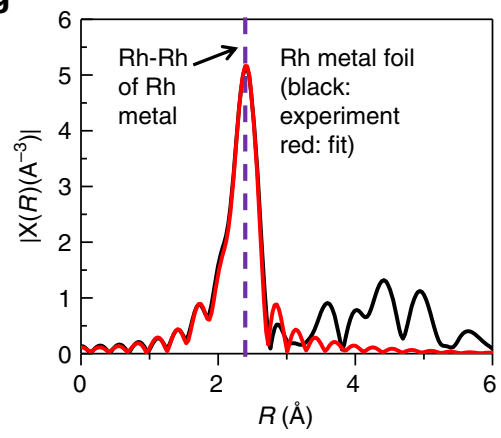

f b

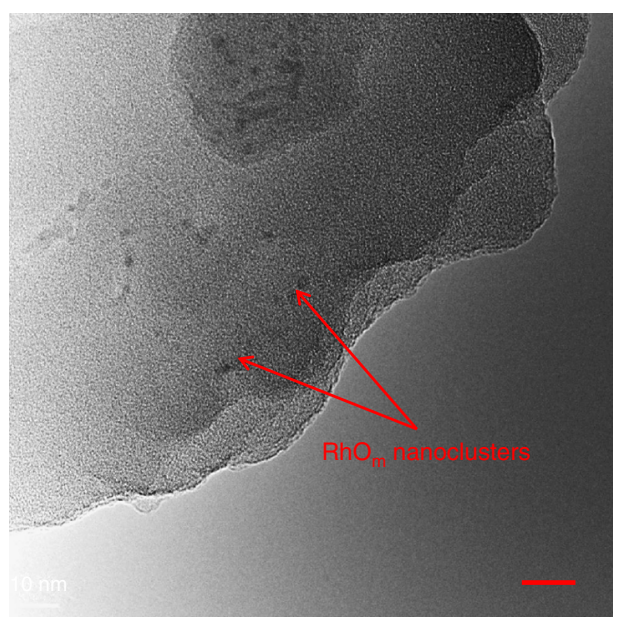

d

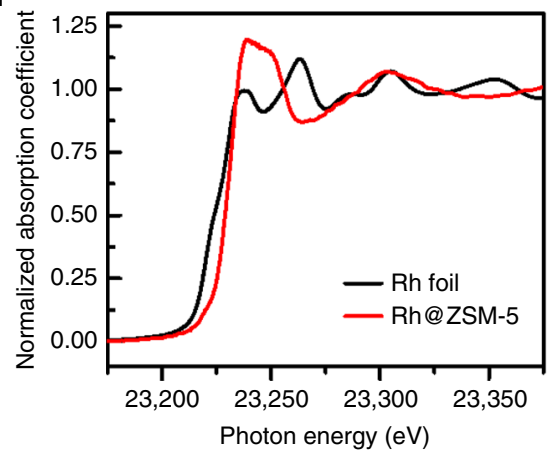

\begin{tabular}{|c|c|c|c|}
\hline & $\mathrm{CN}$ & Distance $(\AA)$ & $\sigma^{2}\left(\AA^{2}\right)$ \\
\hline Rh-O & $5.23 \pm 0.52$ & $2.015 \pm 0.009$ & 0.00348 \\
\hline Rh-(O)-Al & $1.55 \pm 0.66$ & $3.168 \pm 0.032$ & 0.00348 \\
\hline Rh-(O)-Si & $1.68 \pm 0.71$ & $3.514 \pm 0.072$ & 0.00348 \\
\hline
\end{tabular}

h

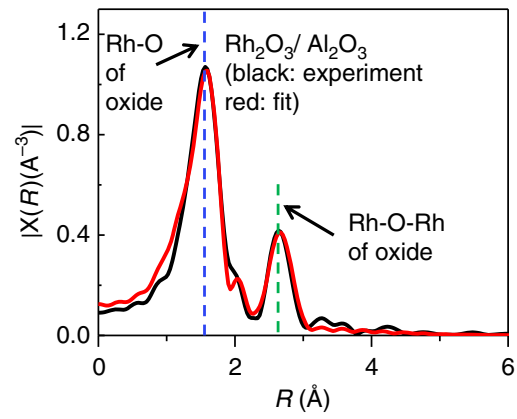

Fig. 1 Structural characterization of isolated rhodium atoms in ZSM-5. a TEM image of particles of 0.10 wt\%Rh/ZSM-5; scale bar: $10 \mathrm{~nm}$. b TEM image of particles of 0.50 wt\%Rh/ZSM-5; scale bar: $10 \mathrm{~nm}$. c Rh 3d XPS peak of 0.10 wt\%Rh/ZSM-5 and 0.50 wt\%Rh/ZSM-5. d Energy space of Rh K-edge of 0.10 wt\% $\mathrm{Rh} / \mathrm{ZSM}-5$ and Rh foil (reference sample) of X-ray absorption near edge spectra (XANES). e r-space of Rh K-edge of experimental (black) and calculated (red) data of the $\mathrm{k}^{2}$-weighted Rh K-edge EXAFS spectra of used $0.10 \mathrm{wt} \% \mathrm{Rh} / \mathrm{ZSM}-5$. $\mathbf{f}$ Coordination number and bond length on average of the used 0.10 wt\%Rh/ ZSM-5. $\mathbf{g}$ r-space of Rh K-edge of experimental (black) and calculated (red) data of the $k^{2}$-weighted Rh K-edge EXAFS spectra of Rh metal foil. $\mathbf{h}$ r-space of Rh K-edge of experimental (black) and calculated (red) data of the $\mathrm{k}^{2}$-weighted Rh K-edge EXAFS spectra of $\mathrm{Rh}_{2} \mathrm{O}_{3}$ nanoparticles supported on $\mathrm{Al}_{2} \mathrm{O}_{3}$ 
space spectrum (Fig. 1h) was clearly observed in our reference sample $\mathrm{Rh}_{2} \mathrm{O}_{3}$ nanoparticles. However, there is lack of $\mathrm{Rh}-\mathrm{O}-\mathrm{Rh}$ peak at $2.60 \AA$ in the r-space spectrum of $0.10 \mathrm{wt} \% \mathrm{Rh} / \mathrm{ZSM}-5$ (black line in Fig. 1e). It shows Rh atoms of our used catalyst do not have the second coordination shell of Rh atoms in terms of lack of $\mathrm{Rh}-\mathrm{O}-\mathrm{Rh}$ and thus there are no rhodium oxide nanoclusters formed in our used catalyst $(0.10 \mathrm{wt} \% \mathrm{Rh} / \mathrm{ZSM}-5)$. Inspired by work of Gates group ${ }^{14,22}$, particularly the assignment of intensity at about $2.7 \AA$ in r-space spectrum of Rh K-edge to $\mathrm{Rh}-\mathrm{O}-\mathrm{Al}$ with a $\mathrm{Rh}-(\mathrm{O})-\mathrm{Al}$ distance of $3.02 \AA^{14,23-25}$, we fit the small peak $(\alpha)$ at about $2.7 \AA$ in Fig. 1e to $\mathrm{Rh}-\mathrm{O}-\mathrm{Al}$. In addition, we fit the intensity at about $3.3 \AA(\beta)$ in r-space of Rh K-edge to $\mathrm{Rh}-\mathrm{O}-\mathrm{Si}$ (Fig. 1e); the coordination numbers of $\mathrm{Al}$ to $\mathrm{Rh}$ through $\mathrm{O}$ atom and $\mathrm{Si}$ to $\mathrm{Rh}$ through $\mathrm{O}$ atom are $1.55 \pm 0.66$ and $1.68 \pm$ 0.71 , respectively; the distances of $\mathrm{Al}$ and $\mathrm{Si}$ atoms to the $\mathrm{Rh}$ atoms are $3.168 \pm 0.032 \AA$ and $3.514 \pm 0.072 \AA$, respectively. Thus, these EXAFS studies show that $\mathrm{Rh}$ atoms of $0.10 \mathrm{wt} \% \mathrm{Rh} / \mathrm{ZSM}-5$ are singly dispersed in micropores of ZSM-5 and each $\mathrm{Rh}$ atom bond with about five oxygen atoms on average. In the following paragraphs, sometimes we used $\mathrm{Rh}_{1} \mathrm{O}_{5} @ Z S M-5$ when we need to point out the coordination environment of the $\mathrm{Rh}$ atoms on average. Supplementary Fig. If schematically shows the structure of a catalytic site of $\mathrm{Rh}_{1} \mathrm{O}_{5}$ anchored in micropores of ZSM-5.

The replacement of Brønsted acid sites (BAS) of H-ZSM-5 by $\mathrm{Rh}$ cations was confirmed with ${ }^{1} \mathrm{H}$ NMR (nuclear magnetic resonance) of $0.10 \mathrm{wt} \% \mathrm{Rh} / \mathrm{ZSM}-5$ and H-ZSM-5. As shown in Supplementary Fig. $2 \mathrm{a}$, the peak at $4.6 \mathrm{ppm}$ was assigned to BAS site of H-ZSM-5 (Supplementary Table 1) ${ }^{26,27}$. It was not obviously observed in the same region of chemical shift in Supplementary Fig. 2b. This difference in Supplementary Fig. 2 suggests that the loss of some BAS sites due to ion exchange of $\mathrm{Rh}^{3+}$ with $\mathrm{H}^{+}$in the IWI process.

Catalytic performance of $\mathrm{Rh}_{1} \mathrm{O}_{5} @ Z S M-5$ at $150{ }^{\circ} \mathrm{C}$. Catalytic activities of pure H-ZSM-5 and as-prepared Rh/ZSM- 5 catalysts were measured by adding $28 \mathrm{mg}$ catalyst to $10 \mathrm{~mL}$ deionized water in a Parr high-pressure reactor (Supplementary Fig. 3b). The aqueous solution with dispersed catalyst particles was continuously, vigorously stirred by a magnetic bar coated with plastic materials at a speed of $600 \mathrm{rpm}$ during catalysis. A mixture of $\mathrm{CH}_{4}, \mathrm{CO}$, and $\mathrm{O}_{2}$ with different partial pressure was introduced to the Parr reactor at room temperature. A portion of these reactant gases with a relatively high-pressure can diffuse to micropores of catalyst dispersed in the solvent $\left(\mathrm{H}_{2} \mathrm{O}\right.$ or dodecane $)$ and thus be catalyzed. Then, the reactor was heated to a set temperature. The reaction temperature of the solvent was directly measured through a thermocouple probe submerged to the solution consisting of the dispersed catalyst particles and solvent in the Parr reactor. The preservation of catalysis temperature for certain amount of time were performed by a temperature controller. This chemical transformation was performed for certain amount of time. The pressure, reaction temperature, and reaction time of each measurement of catalytic performance were given in the following figures and tables. Catalytic reaction under each condition was repeated at least four times.

After each catalytic reaction, the solution in the Parr reactor consisting the used catalyst powder and liquid products was filtrated to separate the used catalyst powder. The clear liquid obtained after filtering the catalyst powder mainly contains acetic acid, methanol, formic acid, and solvent. The product solution was analyzed by ${ }^{1} \mathrm{H}$ NMR and ${ }^{13} \mathrm{C}$ NMR. The measurement was calibrated with 3-(trimethylsilyl)-1-propanesulfonic acid sodium salt (DSS) with chemical shift at $\delta=0.0 \mathrm{ppm}^{11,28}$. A DSS solution was prepared by dissolving DSS to $\mathrm{D}_{2} \mathrm{O}$, making a solution with concentration of DSS in $\mathrm{D}_{2} \mathrm{O}$ at $0.020 \mathrm{wt} \%$. Typically, $0.70 \mathrm{~mL}$ of the obtained clear liquid solution was mixed with $0.10 \mathrm{~mL}$ of asprepared DSS solution in an NMR tube before NMR analysis. The identified oxygenate products were acetic acid $(\delta=2.08 \mathrm{ppm})$, formic acid $(\delta=8.28 \mathrm{ppm})$ and methanol $(\delta=3.33 \mathrm{ppm})$. A solvent suppression program was applied for minimizing the signal originating from $\mathrm{H}_{2} \mathrm{O}$, similar to our previous studies ${ }^{11,28}$. Supplementary Fig. 4 is a representative NMR spectrum of solution after catalysis; peak of DSS was marked on it. To quantify the amounts of products, standard curves of acetic acid, formic acid, and methanol were carefully established and shown in Supplementary Fig. 5. The analysis was described in the Methods section.

With $28 \mathrm{mg}$ of $0.10 \mathrm{wt} \% \mathrm{Rh} / \mathrm{ZSM}-5,226.1 \mu \mathrm{mol}$ of total products (acetic acid, formic acid, and methanol) were produced at $150{ }^{\circ} \mathrm{C}$ in the first hour (entry 4 in Supplementary Table 2). Under the same condition, unfortunately the yields of the total organic compounds formed from $0.50 \mathrm{wt} \% \mathrm{Rh} / \mathrm{ZSM}-5$ (entry 5 in Supplementary Table 2) are similar to $0.10 \mathrm{wt} \% \mathrm{Rh} / \mathrm{ZSM}-5$. The similarity in catalytic performances of the two catalysts shows that the rhodium oxide nanoparticles formed on the surface of $0.50 \mathrm{wt} \% \mathrm{Rh} / \mathrm{ZSM}-5$ are not active for this transformation. In other words, the catalytic activity of $0.10 \mathrm{wt} \% \mathrm{Rh} / \mathrm{ZSM}-5$ in the production of acetic acid was contributed from the $\mathrm{Rh}_{1} \mathrm{O}_{5}$ sites anchored in micropores of ZSM-5 instead of rhodium oxide nanoparticles supported on the external surface of ZSM-5. As the conversions of $\mathrm{CH}_{4}$ in these studies of Fig. 2 and Table 1 are lower than $20 \%$, we used these conversions and yields to calculate the turn-over rates with the equation:

$$
\text { TOR }=\frac{\text { Number of produced moelcules }}{\text { Time of catalytic reaction }(\mathrm{S}) \times \text { Number of acitve sites }\left(\mathrm{Rh}_{1} \mathrm{O}_{5}\right)}
$$

This calculation is based on an assumption that all loaded $\mathrm{Rh}$ atoms are active sites. This calculation was further described in Supplementary Methods. The activities for production of acetic acid and total organic oxygenates including acetic acid, methanol and formic acid at $150^{\circ} \mathrm{C}$ are 0.070 and 0.10 molecules per Rh atom per second (entry 2 of Table 1), respectively.

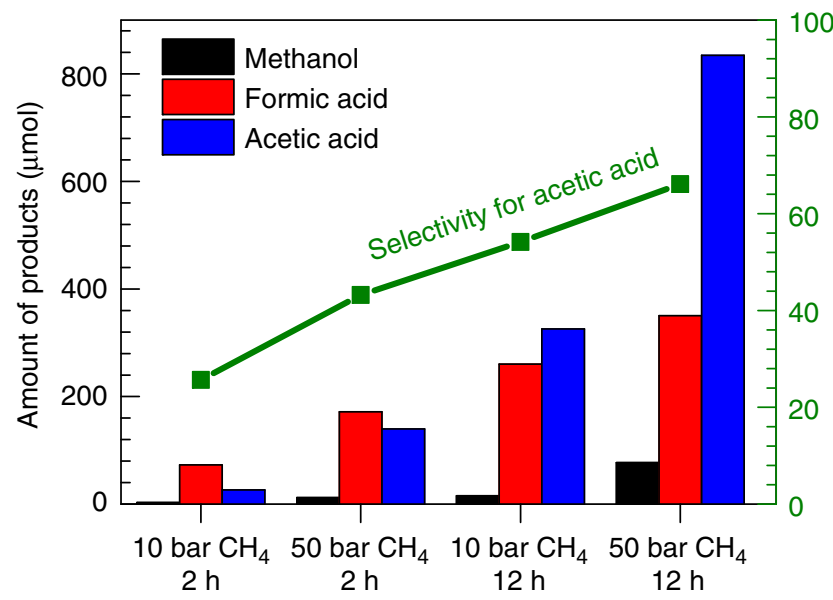

Fig. 2 Catalytic performance of 0.10 wt\%Rh/ZSM-5. Yields of acetic acid formic acid and methanol as well as the selectivity to acetic acid as a function of different pressures of $\mathrm{CH}_{4}$ (10 or 50 bars) and different reaction times ( $2 \mathrm{~h}$ or $12 \mathrm{~h}$ ). $28 \mathrm{mg}$ of $0.10 \mathrm{wt} \% \mathrm{Rh} / \mathrm{ZSM}-5$ was used for each catalysis test. Each catalysis test used 10 bar $\mathrm{CO}$ and 8 bar $\mathrm{O}_{2}$ and certain pressure of $\mathrm{CH}_{4}$ as noted on $x$-axis (10 or 50 bars). The catalysis temperatures of all studies here were $150^{\circ} \mathrm{C}$ 


\section{Table 1 Comparison of TOR for formation of acetic acid or oxygenates including acetic acid, formic acid and methanol on 0.10 wt $\%$ Rh/ZSM-5}

\begin{tabular}{|c|c|c|c|c|c|}
\hline Entry & Catalyst & Catalytic temperature & $\begin{array}{l}\text { TOR of acetic acid } \\
\text { (molecule per site } \\
\text { per second) }\end{array}$ & $\begin{array}{l}\text { TOR of organic oxygenate } \\
\text { (number of molecules per } \\
\text { site per second) }\end{array}$ & $\begin{array}{l}\text { Selectivity for production } \\
\text { of acetic acid }\end{array}$ \\
\hline$\overline{1}$ & 0.10 wt $\%$ Rh/ZSM-5a & $150^{\circ} \mathrm{C}$ & $0.040^{b}$ & $0.099^{b}$ & $40.0 \%$ \\
\hline 2 & 0.10 wt\%Rh/ZSM-5a & $150^{\circ} \mathrm{C}$ & $0.070^{C}$ & $0.10^{c}$ & $70.1 \%$ \\
\hline 3 & $\mathrm{Rh}\left(\mathrm{NO}_{3}\right)_{3}^{a}$ & $150^{\circ} \mathrm{C}$ & $6.3 \times 10^{-6 d}$ & $2.4 \times 10^{-5 d}$ & $26.3 \%$ \\
\hline
\end{tabular}

Table 2 Catalytic performances of $28 \mathrm{mg}$ catalysts of 0.10 wt\%Rh supported on different supports in a mixture of 10 bar $\mathrm{CH}_{4}, 10$ bar $\mathrm{CO}$, and 8 bar $\mathrm{O}_{2}$ at $150^{\circ} \mathrm{C}$ for $3 \mathrm{~h}$ with $10 \mathrm{~mL} \mathrm{H}_{2} \mathrm{O}$ in a high-pressure reactor

\begin{tabular}{llllll} 
Entry & Samples & Methanol $(\mu$ mol) & Formic acid $(\mu$ mol) & Acetic acid $(\mu$ mol) & Total products $(\mu$ mol) \\
\hline 1 & $\mathrm{H}-\mathrm{ZSM}-5$ & 3.67 & 2.28 & 1.87 & 7.82 \\
2 & $0.10 \% \mathrm{Rh} / \mathrm{SiO}_{2}$ & 8.70 & 4.62 & 6.13 & 19.46 \\
3 & $0.10 \% \mathrm{Rh} / \mathrm{Al}_{2} \mathrm{O}_{3}$ & 5.68 & 0.91 & 3.05 & 9.64 \\
\hline Acetic acid, formic acid, and methanol were identified as products. Reactants on pure $\mathrm{H}-\mathrm{ZSM}-5$ was also performed at the same conditions as blank experiment (entry 1)
\end{tabular}

To check whether Rh atoms anchored in micropores of ZSM-5 could detach from ZSM-5, the clear solution was obtained by filtration for removal of $\mathrm{Rh} / \mathrm{ZSM}-5$ catalyst particles from the solution after catalysis at $150^{\circ} \mathrm{C}$ for $12 \mathrm{~h}$. ICP-AES test of this solution shows that only $2 \%$ of the total $\mathrm{Rh}$ atoms of $28 \mathrm{mg}$ of 0.10 wt $\% \mathrm{Rh} / \mathrm{ZSM}-5$ detached from ZSM-5 to solution. Thus, most $\mathrm{Rh}$ atoms remained in ZSM-5 after catalysis. Due to the negligible amount of $\mathrm{Rh}^{3+}$ detached from $0.10 \mathrm{wt} \% \mathrm{Rh} / \mathrm{ZSM}-5$ and the extremely low TOF of free $\mathrm{Rh}^{3+}$ in solution evidenced in entry 3 in Table 1 , contribution of the detached $\mathrm{Rh}^{3+}$ to the measured catalytic activity in formation of acetic acid is negligible. It suggests that the anchored $\mathrm{Rh}$ atoms are the active sites.

To further confirm the contribution of $\mathrm{Rh}_{1} \mathrm{O}_{5}$ sites to the formation of acetic acid, control experiments were performed on these catalysts including $28 \mathrm{mg}$ of $\mathrm{H}-\mathrm{ZSM}-5,28 \mathrm{mg}$ of $0.10 \mathrm{wt} \%$ $\mathrm{Rh} / \mathrm{SiO}_{2}$ and $28 \mathrm{mg}$ of $0.10 \mathrm{wt} \% \mathrm{Rh} / \mathrm{Al}_{2} \mathrm{O}_{3}$ under the exactly same condition as that of $28 \mathrm{mg} 0.10 \mathrm{wt} \% \mathrm{Rh} / \mathrm{ZSM}-5$ at $150{ }^{\circ} \mathrm{C}$ in the mixture of 10 bar $\mathrm{CH}_{4}, 10$ bar $\mathrm{CO}$ and 8 bar $\mathrm{O}_{2}$ for $4 \mathrm{~h}$. As shown in Table 2, the amounts of acetic acid, formic acid, or methanol produced on $28 \mathrm{mg}$ of $0.10 \mathrm{wt} \% \mathrm{Rh} / \mathrm{SiO}_{2}$ and $28 \mathrm{mg}$ of $0.10 \mathrm{wt} \%$ $\mathrm{Rh} / \mathrm{Al}_{2} \mathrm{O}_{3}$ are lower than $10 \mu \mathrm{mol}$, which are at the level of error bar. All the reported yields in this communication are the measured products formed from $28 \mathrm{mg}$ catalyst. The yield could be shown as $\mu \mathrm{mol} / \mathrm{gram}$ catalyst by multiplying a factor of $\frac{1000 \mathrm{mg} / \mathrm{gram}}{28 \mathrm{mg}}$. For example, the measured yields of methanol and acetic acid on $28 \mathrm{mg}$ of $0.10 \% \mathrm{Rh} / \mathrm{SiO}_{2}$ are 8.70 and $6.13 \mu \mathrm{mol}$, respectively; if they are multiplied by the factor $\frac{1000 \mathrm{mg} / \mathrm{gram}}{28 \mathrm{mg}}$ they seem to indicate that $310 \mu \mathrm{mol}$ methanol and $218 \mu \mathrm{mol}$ acetic acid could form from one gram of $0.10 \% \mathrm{Rh} / \mathrm{SiO} \mathrm{S}_{2}$ catalyst. Here, the multiplication is not meaningful since the values in Table 2 are at the uncertainty level. As the measured $8.70 \mu \mathrm{mol}$ methanol and $6.13 \mu \mathrm{mol}$ acetic acid from $28 \mathrm{mg} 0.10 \% \mathrm{Rh} / \mathrm{SiO}_{2}$ catalyst are in the range of error bar of these measurements, these values are not used to predict activity of 1 gram to compare with other catalysts. Even if the multiplication factor were applied, the activity of $0.10 \% \mathrm{Rh} / \mathrm{SiO}_{2}$ is significantly lower than $0.10 \mathrm{wt} \% \mathrm{Rh} /$
ZSM-5. For instance, $218 \mu \mathrm{mol}$ acetic acid from per gram $0.10 \%$ $\mathrm{Rh} / \mathrm{SiO}_{2}$ calculated from the measured $6.13 \mu \mathrm{mol}$ acetic acid per $28 \mathrm{mg}$ is still much lower than $5000 \mu \mathrm{mol}$ acetic acid from per gram $0.10 \mathrm{wt} \% \mathrm{Rh} / \mathrm{ZSM}-5$ calculated from the measured $140 \mu \mathrm{mol}$ acetic acid per $28 \mathrm{mg}$ catalyst. In conclusion, these control samples in terms of Rh supported on these nonporous oxides and even on a couple of commonly used reducible oxides are not active for the production of acetic acid or methanol from coupling of $\mathrm{CH}_{4}$ with $\mathrm{CO}$ and $\mathrm{O}_{2}$. Thus, these studies suggest the significant contribution of $\mathrm{Rh}_{1} \mathrm{O}_{5}$ sites encapsulated in ZSM-5 to the formation of acetic acid.

The participation of all these three reactants $\left(\mathrm{CH}_{4}, \mathrm{CO}\right.$, and $\mathrm{O}_{2}$ ) was confirmed with three parallel studies on $0.10 \mathrm{wt} \% \mathrm{Rh} /$ ZSM-5 under the exactly same catalytic condition as listed in Supplementary Fig. 6a, b, c; in each of these studies, only two of the three reactants were introduced to the Parr reactor; none of these studies produced acetic acid, formic acid, or methanol due to the lack of the third reactant gas. Those studies clearly show that all the three gases $\left(\mathrm{CH}_{4}, \mathrm{CO}\right.$, and $\left.\mathrm{O}_{2}\right)$ are necessary reactants for the formation of $\mathrm{CH}_{3} \mathrm{COOH}$. The necessity of the three reactants was supported by DFT calculations described later.

Participation of molecular $\mathrm{O}_{2}$ in synthesis of acetic acid. Here, we used low-cost molecular oxygen $\left(\mathrm{O}_{2}\right)$ or compressed air as oxidant in oxidative transformation of $\mathrm{CH}_{4}$ and $\mathrm{CO}$ to acetic acid. To further confirm the direct participation of molecular $\mathrm{O}_{2}$, we performed catalysis at different pressures of $\mathrm{O}_{2}(2,4,8,12$, and 16 bar) but all other conditions are the same in these parallel studies; in each of these parallel studies, $28 \mathrm{mg}$ of $0.10 \mathrm{wt} \% \mathrm{Rh} /$ $\mathrm{ZSM}-5$ was added to $10 \mathrm{~mL} \mathrm{H}_{2} \mathrm{O}$. The reaction was performed at $150{ }^{\circ} \mathrm{C}$ for $2 \mathrm{~h}$ in a mixture of 35 bar $\mathrm{CH}_{4}, 10$ bar $\mathrm{CO}$ and different pressures of $\mathrm{O}_{2}$, in order to investigate the correlation of yields of products (acetic acid, formic acid, and methanol) with pressure of $\mathrm{O}_{2}$. As shown in Fig. 3a, highest yields of acetic acid and formic acid were obtained from the catalysis using 8 bar $\mathrm{O}_{2}$. The increase of yield of acetic acid and formic acid along the increase of $\mathrm{O}_{2}$ pressure shows that $\mathrm{O}_{2}$ does participate in the formation of acetic 
a

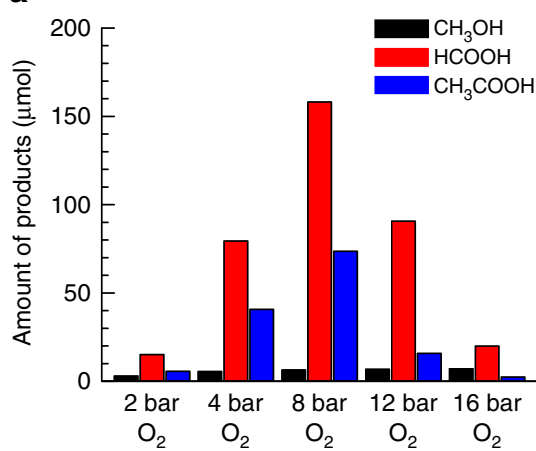

b

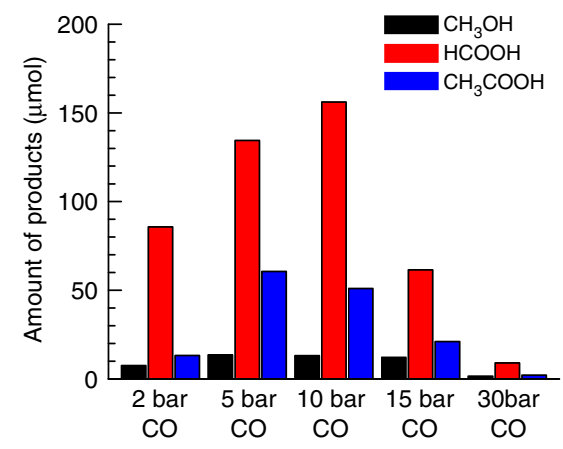

C

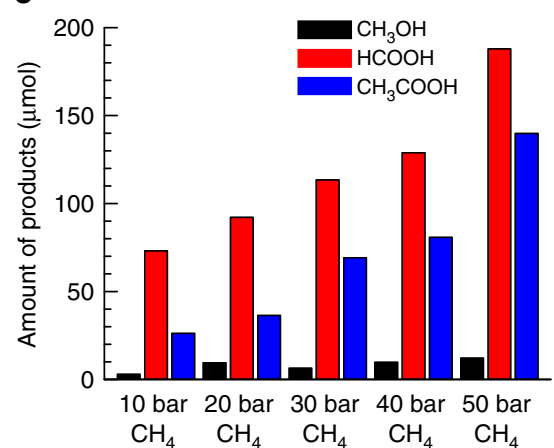

Fig. 3 Influence of partial pressure $\mathrm{O}_{2}, \mathrm{CO}$ and $\mathrm{CH}_{4}$ on catalytic performances. Yields of methanol (black), formic acid (blue), and acetic acid (red) in the chemical transformation of $\mathrm{CH}_{4}$ at $150{ }^{\circ} \mathrm{C}$ in aqueous solutions at different pressure of $\mathrm{O}_{2}, \mathrm{CO}_{1} \mathrm{CH}_{4}$. a 35 bar $\mathrm{CH}_{4}, 10$ bar $\mathrm{CO}_{1}$ and different pressure of $\mathrm{O}_{2}$ at $150{ }^{\circ} \mathrm{C}$ for $2 \mathrm{~h}$. b 50 bar $\mathrm{CH}_{4}, 8$ bar $\mathrm{O}_{2}$, and different pressure of $\mathrm{CO}$ at $150{ }^{\circ} \mathrm{C}$ for $1.5 \mathrm{~h}$. $\mathbf{c} 10$ bar $\mathrm{CO}_{,} 8$ bar $\mathrm{O}_{2}$ and different pressure of $\mathrm{CH}_{4}$ at $150{ }^{\circ} \mathrm{C}$ for $2 \mathrm{~h}$

acid and formic acid. It is expected that high coverage of oxygen atoms on a $\mathrm{Rh}$ atom achieved with high-pressure $\mathrm{O}_{2}$ could saturate $\mathrm{Rh}_{1}$ atom with oxygen atoms, which poisons catalytic sites and thus results in a low yield of oxygenates at high pressure of $\mathrm{O}_{2}$.

Direct participation of CO to synthesis of acetic acid. To further confirm the participation of $\mathrm{CO}$ in the formation of acetic acid, influence of the partial pressure of $\mathrm{CO}$ on both the conversion of $\mathrm{CH}_{4}$ and selectivity for production of acetic acid was investigated through parallel studies (Fig. 3b). In each of these studies, the partial pressures of $\mathrm{CH}_{4}$ and $\mathrm{O}_{2}$ were fixed at 50 and 8 bar, respectively. However, the pressures of $\mathrm{CO}$ in the five studies are 2, 5, 10,15, and 30 bar. The increase of the amount of acetic acid while CO pressure was increased from 2 to 10 bar suggests that $\mathrm{CO}$ directly participates into the formation of acetic acid. However, the lack of activity for production of acetic acid at 30 bar CO showed that catalyst sites were blocked at such a highpressure of CO. Clearly, CO molecules must have directly interacted with the Rh cations. At high-pressure of $\mathrm{CO}$, high coverage of $\mathrm{CO}$ could saturate the coordination of $\mathrm{a} \mathrm{Rh}_{1}$ atom and thus deactivate this catalyst. We measured the concentrations of $\mathrm{Rh}$ in the liquid ( $\alpha$ ) after filtration of the catalyst experienced the catalysis at 10 bar $\mathrm{CO}, 50$ bar $\mathrm{CH}_{4}$, and 8 bar $\mathrm{O}_{2}$ for $2.5 \mathrm{~h}$, and in another liquid $(\beta)$ after filtration of the catalyst experienced the catalysis at 30 bar CO, 50 bar $\mathrm{CH}_{4}$, and 8 bar $\mathrm{O}_{2}$. The amounts of $\mathrm{Rh}$ atoms in the liquids $\alpha$ and $\beta$ are $2.0 \%$ and $13.0 \%$ of all $\mathrm{Rh}$ atoms of $28 \mathrm{mg}$ of $0.10 \mathrm{wt} \% \mathrm{Rh} / \mathrm{ZSM}-5$, respectively. Thus, the much larger loss of Rh atoms at high-pressure of CO (30 bar) suggests that $\mathrm{Rh}$ atoms formed carbonyl in $\mathrm{CO}$ at high-pressure and some of these formed rhodium carbonyl species desorbed from micropores and then dissolved in the solution. Thus, some Rh species detached at high pressure of CO.

A molecular-level evidence on direct participation of $\mathrm{CO}$ in the synthesis of acetic acid is the following isotope experiment. 0.7 bar ${ }^{13} \mathrm{CO}$ (Aldrich, 99\%, total pressure 2.5 bar) was mixed with 6.3 bar of $\mathrm{CO}, 14$ bar $\mathrm{CH}_{4}$, and 8 bar $\mathrm{O}_{2}$ for catalysis of $10 \mathrm{~h}$ (Fig. 4a). As the chemical shift of ${ }^{13} \mathrm{CH}_{3} \mathrm{OH}$ in ${ }^{13} \mathrm{C}$ spectrum can be readily distinguished from acetic acid and formic acid, $40 \mu \mathrm{mol}$ of ${ }^{13} \mathrm{CH}_{3} \mathrm{OH}$ (Aldrich, 99 at\%) was added to the collected solution after catalysis as a reference to quantify the amount of potential isotope products ${ }^{13} \mathrm{CH}_{3} \mathrm{COOH}, \mathrm{CH}_{3}{ }^{13} \mathrm{COOH}$, or $\mathrm{H}^{13} \mathrm{COOH}$. As the unlabeled $\mathrm{CO}$ gas has a natural abundance of ${ }^{13} \mathrm{C}$ of $1.10 \%$, a small amount of $\mathrm{CH}_{3}{ }^{13} \mathrm{COOH}$ or $\mathrm{H}^{13} \mathrm{COOH}$ can form from the natural $1.10 \%{ }^{13} \mathrm{CO}$ of unlabeled $\mathrm{CO}$ gas tank. Contrast experiments using the mixture of 7 bar of $\mathrm{CO}, 14$ bar $\mathrm{CH}_{4}$, and
8 bar $\mathrm{O}_{2}$ were performed (Fig. $4 \mathrm{~b}$ ). The intensity ratio of the formed $\mathrm{CH}_{3}{ }^{13} \mathrm{COOH}$ to ${ }^{13} \mathrm{CH}_{3} \mathrm{OH}$ in the solution of isotope experiment using ${ }^{13} \mathrm{CO}$ (Fig. $4 \mathrm{a}$ ) is obviously larger than those formed in the contrast experiment using unlabeled $\mathrm{CO}$ (Fig. 4b) by 6.4 times; in addition, the intensity ratio of $\mathrm{H}^{13} \mathrm{COOH}$ to ${ }^{13} \mathrm{CH}_{3} \mathrm{OH}$ in isotope experiment (Fig. 4a) is higher than that in the contrast experiment by 2.6 times (Fig. 4b). They suggested that the $\mathrm{C}^{\prime}$ atoms of $\mathrm{CH}_{3} \mathrm{C}^{\prime} \mathrm{OOH}$ and $\mathrm{HC}^{\prime} \mathrm{OOH}$ came from $\mathrm{C}^{\prime} \mathrm{O}$ molecules. Notably, the intensity ratio of ${ }^{13} \mathrm{CH}_{3} \mathrm{COOH}$ to reference $\left({ }^{13} \mathrm{CH}_{3} \mathrm{OH}\right)$ in isotope experiment (Fig. $\left.4 \mathrm{a}\right)$ is the same as the ratio of the contrast experiment (Fig. 4b). It suggests that the $\mathrm{C}$ atoms of $\mathrm{CH}_{3}$ of $\mathrm{CH}_{3} \mathrm{COOH}$ do not come from the reactant CO.

One potential pathway to form acetic acid is the coupling of $\mathrm{CO}$ with a formed formic acid molecule; if so, yield of acetic acid should increase along the increase of CO pressure. However, as shown in Fig. $3 b$ yield of acetic acid decreases along with the increase of $\mathrm{CO}$ pressure ( $\geq 10 \mathrm{bar}$ ). Thus, coupling formic acid with CO to form acetic acid is not a pathway. To further check the possibility of reaction between $\mathrm{HCOOH}$ and $\mathrm{CO}$ to form acetic acid, we performed three control experiments at $150^{\circ} \mathrm{C}$ for $3 \mathrm{~h}$ under the following conditions including mixture of $28 \mathrm{mg}$ $0.10 \mathrm{wt} \% \mathrm{Rh} / \mathrm{ZSM}-5,108 \mu \mathrm{mol} \mathrm{HCOOH}$, and $10 \mathrm{~mL}$ DI $\mathrm{H}_{2} \mathrm{O}$ without any CO, mixture of $28 \mathrm{mg} 0.10 \mathrm{wt} \% \mathrm{Rh} / \mathrm{ZSM}-5,108 \mu \mathrm{mol}$ $\mathrm{HCOOH}$, and $10 \mathrm{~mL} \mathrm{DI} \mathrm{H}_{2} \mathrm{O}$ with 5 bar $\mathrm{CO}$, and mixture of 28 mg $0.10 \mathrm{wt} \% \mathrm{Rh} / \mathrm{ZSM}-5,108 \mu \mathrm{mol} \mathrm{HCOOH}$, and $10 \mathrm{~mL} \mathrm{DI} \mathrm{H}_{2} \mathrm{O}$ with 10 bar CO. As shown in Supplementary Fig. 7, no acetic acid was formed in these experiments.

Direct participation of $\mathrm{CH}_{4}$ in formation of $\mathrm{CH}_{3} \mathbf{C O O H}$. The influence of $\mathrm{CH}_{4}$ pressure on the catalytic performance was explored at $150{ }^{\circ} \mathrm{C}$ under a mixture of 10 bar $\mathrm{CO}$ and 8 bar $\mathrm{O}_{2}$ and different pressure of $\mathrm{CH}_{4}(10,20,30,40$, and 50 bar) for $2 \mathrm{~h}$ (Fig. 3c). The progressive increase of yield of acetic acid along the increase of $\mathrm{CH}_{4}$ pressure shows that $\mathrm{CH}_{4}$ directly participates into the formation of acetic acid (Fig. 3c), which excluded a pathway in which $\mathrm{CH}_{4}$ couples with formic acid to form acetic acid. If acetic acid were formed from a coupling of formic acid with $\mathrm{CH}_{4}$, the amount of formic acid should have decreased along the increase of pressure of $\mathrm{CH}_{4}$ since more formic acid should have been consumed along with the increased amount of $\mathrm{CH}_{4}$.

To elucidate the source of carbon atoms at the molecular level, ${ }^{13} \mathrm{CH}_{4}$ isotope experiments were performed. 0.7 bar ${ }^{13} \mathrm{CH}_{4}$ (Aldrich, 99 at\%) was mixed with 13.3 bar of $\mathrm{CH}_{4}, 7.0$ bar $\mathrm{CO}$, and 8.0 bar $\mathrm{O}_{2}$ for isotope experiment on $28 \mathrm{mg}$ of $0.10 \mathrm{wt} \% \mathrm{Rh} /$ ZSM-5 at $170{ }^{\circ} \mathrm{C}$ for $10 \mathrm{~h}$ (Fig. 4c). A control experiment using 14 
a

0.7 bar ${ }^{13} \mathrm{CO}+6.3$ bar $\mathrm{CO}+14$ bar $\mathrm{CH}_{4}+8$ bar $\mathrm{O}_{2}$

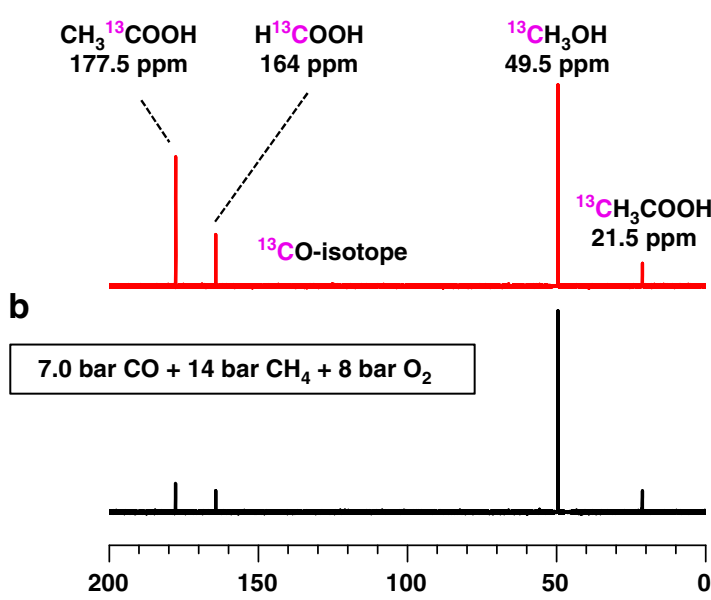

C

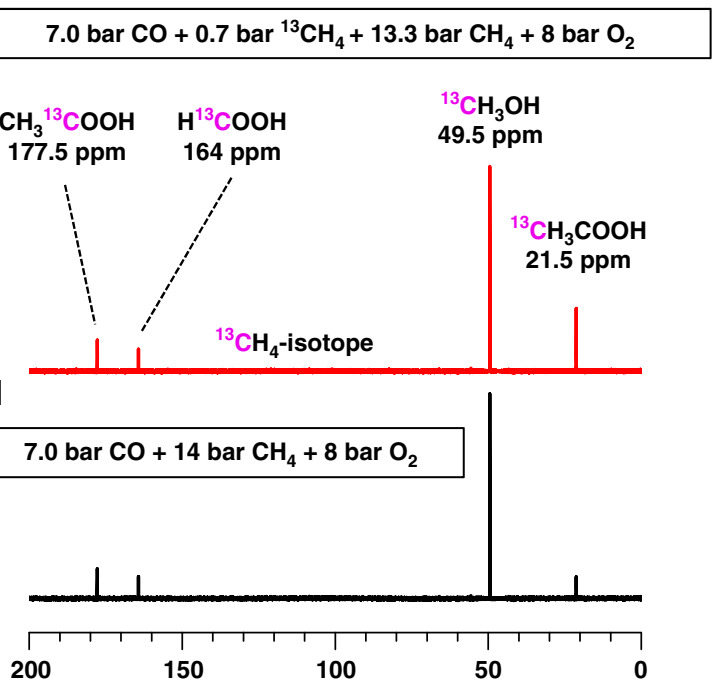

Fig. $4{ }^{13} \mathrm{C}$ NMR studies of reaction using ${ }^{13} \mathrm{CO}$ or ${ }^{13} \mathrm{CH}_{4} \cdot{ }^{13} \mathrm{C}$ NMR spectra of products of acetic acid, formic acid, and methanol on $28 \mathrm{mg} 0.10 \mathrm{wt} \% \mathrm{Rh} /$ $\mathrm{ZSM}-5$ at $170{ }^{\circ} \mathrm{C}$ for $10 \mathrm{~h}$ in gas of a mixture of 0.7 bar ${ }^{13} \mathrm{CO}, 6.3$ bar $\mathrm{CO}, 14$ bar $\mathrm{CH}_{4}$, and 8 bar $\mathrm{O}_{2}, \mathbf{b}$ mixture of 7 bar $\mathrm{CO}_{1}, 14$ bar $\mathrm{CH}_{4}$, and 8 bar $\mathrm{O}_{2}, \mathbf{c}$ mixture of 7 bar $\mathrm{CO}, 0.7$ bar ${ }^{13} \mathrm{CH}_{4}, 13.3$ bar $\mathrm{CH}_{4}$, and 8 bar $\mathrm{O}_{2}$, and $\mathbf{d}$ mixture of 7 bar $\mathrm{CO}, 14$ bar $\mathrm{CH}_{4}$, and 8 bar $\mathrm{O}_{2}$. a and $\mathbf{b}$ are isotope experiments; $\mathbf{c}$ and d are their corresponding contrast experiments

bar unlabeled $\mathrm{CH}_{4}$ was performed under the exactly same catalytic condition (Fig. 4d). ${ }^{13} \mathrm{CH}_{3} \mathrm{COOH}$ were formed in the two experiments. However, their ratio of ${ }^{13} \mathrm{CH}_{3} \mathrm{COOH}$ to reference $\left({ }^{13} \mathrm{CH}_{3} \mathrm{OH}\right)$ when ${ }^{13} \mathrm{CH}_{4}$ was used (Fig. $4 \mathrm{c}$ ), is much larger than that when unlabeled $\mathrm{CH}_{4}$ was used (Fig. 4d). This difference shows that the carbon atom of $\mathrm{CH}_{3}$ of acetic acid comes from $\mathrm{CH}_{4}$ instead of $\mathrm{CO}$. If $\mathrm{C}$ atoms of $\mathrm{C}=\mathrm{O}$ of $\mathrm{CH}_{3} \mathrm{COOH}$ could come from $\mathrm{CH}_{4}$, the ratio of $\mathrm{CH}_{3}{ }^{13} \mathrm{COOH}$ to reference $\left({ }^{13} \mathrm{CH}_{3} \mathrm{OH}\right)$ in Fig. $4 \mathrm{c}$ would be much larger than the ratio in Fig. $4 \mathrm{~d}$ since the experiment of Fig. $4 \mathrm{~d}$ contains significant amount of ${ }^{13} \mathrm{CH}_{4}$. In fact, in both experiments (Fig. 4c, d), we did observe small amount of $\mathrm{CH}_{3}{ }^{13} \mathrm{COOH}$ but there is no difference between their ratios to reference $\left({ }^{13} \mathrm{CH}_{3} \mathrm{OH}\right)$ in the experiments of both Fig. $4 c$, d. Here, the formation of $\mathrm{CH}_{3}{ }^{13} \mathrm{COOH}$ is due to the natural abundance of ${ }^{13} \mathrm{CO}$ in unlabeled $\mathrm{CO}$. Thus, $\mathrm{CO}$ does not contribute to the formation of $\mathrm{CH}_{3}$ of $\mathrm{CH}_{3} \mathrm{COOH}$.

Direct coupling of reactants for formation of acetic acid. It is noted that the amounts of the observed methanol in any of our studies of this work are always much lower than acetic acid and formic acid. One potential argument for the low yield of methanol could be that methanol has been formed but it could have acted as an intermediate compound in the formation of acetic acid; in other words, formic acid could have been consumed through coupling with CO to form acetic acid. Depending on whether $\mathrm{CH}_{3} \mathrm{OH}$ could act as an intermediate product in the formation of acetic acid or not, two categories of potential pathways $\alpha$ and $\beta$ were proposed in Fig. 5a. In potential pathway a, $\mathrm{CH}_{4}$ couples with $\mathrm{CO}$ to directly form acetic acid; methanol is not an intermediate product of this type of reaction pathway. In potential pathway $\beta$, however, $\mathrm{CH}_{3} \mathrm{OH}$ is an intermediate product and then be consumed in the formation of acetic acid; $\mathrm{CH}_{4}$ is first oxidized to $\mathrm{CH}_{3} \mathrm{OH}$ (the first step) and then $\mathrm{CH}_{3} \mathrm{OH}$ couples with $\mathrm{CO}$ to form acetic acid (the second step); the second step of the potential pathway $\beta$ is called carbonylation of methanol by $\mathrm{CO}$; it is in fact the Monsanto process ${ }^{29-31}$. In order to identify whether $\mathrm{CH}_{3} \mathrm{OH}$ carbonylation (pathway $\beta$ ) could be a pathway for the production of acetic acid on our catalyst $\mathrm{Rh}_{1} \mathrm{O}_{5} @ Z S M-5$, carefully designed isotope experiments described in Supplementary Methods were performed.
These isotope experiments show that acetic acid cannot be formed from carbonylation of methanol by $\mathrm{CO}$ on our catalyst. In one isotope-labeled experiment, $1.0 \mathrm{mmol}$ isotope-labeled ${ }^{13} \mathrm{CH}_{3} \mathrm{OH}$ (99 atom $\%{ }^{13} \mathrm{C}$, Aldrich) was added to $10 \mathrm{~mL}$ deionized $\mathrm{H}_{2} \mathrm{O}$ before introduction of 10 bar $\mathrm{CH}_{4}, 5$ bar $\mathrm{CO}$, and 4 bar $\mathrm{O}_{2}$ to the Parr reactor. If $\mathrm{CH}_{3} \mathrm{OH}$ could not be an intermediate for formation of acetic acid, the added ${ }^{13} \mathrm{CH}_{3} \mathrm{OH}$ would not particulate into the formation of isotope-labeled acetic acid, ${ }^{13} \mathrm{CH}_{3} \mathrm{COOH}$. Thus, no ${ }^{13} \mathrm{CH}_{3} \mathrm{COOH}$ could be observed if carbonylation of methanol by $\mathrm{CO}$ would not be involved (possibility 1 in Fig. 5b). The NMR spectrum of the solution of products formed in the reactor having ${ }^{12} \mathrm{CH}_{4},{ }^{12} \mathrm{CO}$, and $\mathrm{O}_{2}$ in $\mathrm{H}_{2} \mathrm{O}\left({ }^{13} \mathrm{CH}_{3} \mathrm{OH}\right.$ was not added) after reaction of $2 \mathrm{~h}$ was presented in Fig. $5 \mathrm{c}$. Figure $5 \mathrm{~d}$ is the NMR spectrum of the products formed after the catalysis for $1 \mathrm{~h}$ under a condition of mixture of ${ }^{13} \mathrm{CH}_{3} \mathrm{OH},{ }^{12} \mathrm{CH}_{4},{ }^{12} \mathrm{CO}$, and $\mathrm{O}_{2}$ at $150^{\circ} \mathrm{C}$. The observed peaks $\mathrm{A}, \mathrm{B}, \mathrm{C}, \mathrm{D}$, and $\mathrm{E}$ in Fig. $5 \mathrm{~d}$ were assigned to $\mathrm{CH}_{3} \mathrm{COOH}, \mathrm{CH}_{3} \mathrm{OH}, \mathrm{HCOOH},{ }^{13} \mathrm{CH}_{3} \mathrm{OH}$, and $\mathrm{H}^{13} \mathrm{COOH}$, respectively. As neither peak of $\mathrm{H}$ atoms of ${ }^{13} \mathrm{CH}_{3}$ of ${ }^{13} \mathrm{CH}_{3} \mathrm{COOH}$ in ${ }^{1} \mathrm{H}$ spectrum nor peak of ${ }^{13} \mathrm{C}$ atoms of $\mathrm{CH}_{3}{ }^{13} \mathrm{COOH}$ in ${ }^{13} \mathrm{C}$ spectrum was observed in the NMR, pathway $\beta$ is not a pathway for formation of acetic acid. Thus, these isotope studies showed that acetic acid is not formed from carbonylation of methanol by $\mathrm{CO}$. Additionally, $\mathrm{H}^{13} \mathrm{COOH}$ was observed clearly in Fig. 5 d, suggesting that ${ }^{13} \mathrm{CH}_{3} \mathrm{OH}$ can be oxidized to $\mathrm{H}^{13} \mathrm{COOH}$ under the current catalytic condition.

We also performed the dry reforming of $\mathrm{CH}_{4}$ by $\mathrm{CO}_{2}$ by introducing 30 bar $\mathrm{CH}_{4}$ and 30 bar $\mathrm{CO}_{2}$ to the reactor containing $10 \mathrm{~mL} \mathrm{H} \mathrm{H}_{2} \mathrm{O}$ and well dispersed $28 \mathrm{mg}$ of $0.10 \mathrm{wt} \% \mathrm{Rh} / \mathrm{ZSM}-5$. The reactor was heated to $150{ }^{\circ} \mathrm{C}$ and remained at $150{ }^{\circ} \mathrm{C}$ for $5 \mathrm{~h}$ and then cooled to $10^{\circ} \mathrm{C}$ in ice water. As shown in Supplementary Fig. 6d, NMR test shows none of these products (acetic acid, formic acid, and methanol) was formed.

Ready separation of products from hydrophobic solvent. The above chemical transformation was performed in aqueous solution. As the products of this chemical transformation, acetic acid, formic acid, and methanol are hydrophilic, it is not readily to separate these hydrophilic products from water. To make these hydrophilic products automatically separate from solvent after synthesis, a hydrophobic solvent, $n$-dodecane was used. As shown 
a

$\begin{array}{ll}\text { Pathway } \alpha: & 2 \mathrm{CH}_{4}+2 \mathrm{CO}+\mathrm{O}_{2}=2 \mathrm{CH}_{3} \mathrm{COOH} \\ \text { Pathway } \beta: & \mathrm{CH}_{4} \longrightarrow \mathrm{CH}_{3} \mathrm{OH} \stackrel{+\mathrm{CO}}{\longrightarrow} \mathrm{CH}_{3} \mathrm{COOH}\end{array}$

b

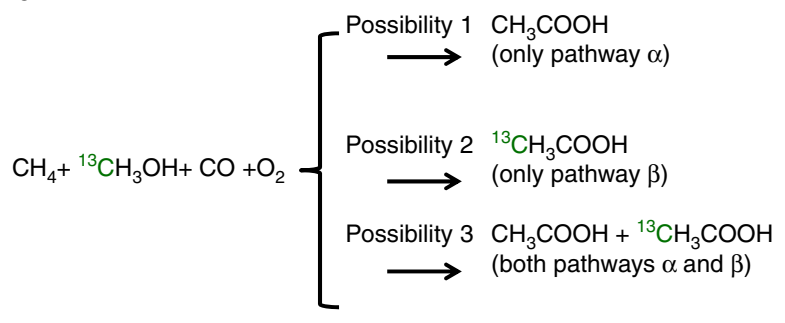

C

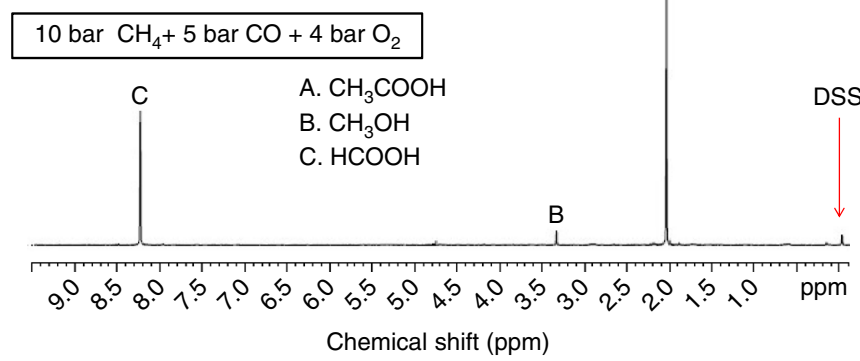

d

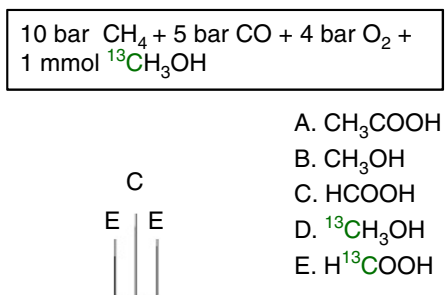

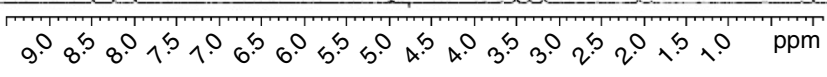

Chemical shift (ppm)

Fig. 5 Isotope studies for elucidating whether acetic acid could be formed through coupling methanol with $\mathrm{CO}$. a Two potential pathways $\alpha$ and $\beta$ for production of acetic acid; in pathway $\alpha, \mathrm{CH}_{3} \mathrm{OH}$ is not an intermediate compound for formation of $\mathrm{CH}_{3} \mathrm{COOH}$; in pathway $\beta, \mathrm{CH}_{3} \mathrm{OH}$ is an intermediate compound for formation of $\mathrm{CH}_{3} \mathrm{COOH}$. b Potential catalytic products formed from 0.10 wt\%Rh/ZSM-5 in the mixture of ${ }^{13} \mathrm{CH}_{3} \mathrm{OH}$ and $\mathrm{H}_{2} \mathrm{O}$ in solution under mixture of $\mathrm{CH}_{4}, \mathrm{CO}$, and $\mathrm{O}_{2}$ if the transformation of $\mathrm{CH}_{4}, \mathrm{CO}$, and $\mathrm{O}_{2}$ follows pathway $\alpha, \beta$, or both $\alpha$ and $\beta$. c NMR spectra of the products formed from $28 \mathrm{mg}$ of $0.10 \mathrm{wt} \% \mathrm{Rh} / \mathrm{ZSM}-5$ after reaction in 10 bar $\mathrm{CH}_{4}, 5$ bar CO, and 4 bar $\mathrm{O}_{2}$ at $150^{\circ} \mathrm{C}$ for $1 \mathrm{~h}$; there was no any isotope-labeled methanol, ${ }^{13} \mathrm{CH}_{3} \mathrm{OH}$ added to the rector before this catalysis test. $\mathbf{d}$ NMR spectra of the products formed from $28 \mathrm{mg}$ of 0.10 wt\%Rh/ZSM-5 after reaction in 10 bar $\mathrm{CH}_{4}, 5$ bar $\mathrm{CO}$, and 4 bar $\mathrm{O}_{2}$ at $150{ }^{\circ} \mathrm{C}$ for 1 h.; notably, $1.0 \mathrm{mmol}{ }^{13} \mathrm{CH}_{3} \mathrm{OH}$ was added to $\mathrm{H}_{2} \mathrm{O}$ before this catalysis test

in Supplementary Fig. $828 \mathrm{mg} 0.10 \mathrm{wt} \% \mathrm{Rh} / \mathrm{ZSM}-5$ in $10 \mathrm{~mL} n$ dodecane in the mixture of 30 bar $\mathrm{CH}_{4}, 10$ bar $\mathrm{CO}$, and 5 bar $\mathrm{O}_{2}$ is definitely active for the formation of acetic acid. The significant advantage of using the hydrophobic solvent is that the hydrophilic products of this reaction including acetic acid, methanol, and formic acid can be readily separated from the hydrophobic solvent, without or with a low energy cost.

Feature of this mild oxidation of methane in solution. $\mathrm{CH}_{4}$ and $\mathrm{CO}$ can be oxidized with different oxidants including $\mathrm{O}_{2}$, concentrated $\mathrm{H}_{2} \mathrm{SO}_{4}$, or a superacid ${ }^{32-34}$ by using homogeneous catalyst $^{32}$, in which acetic acid and other products (formic acid and methanol) were formed. One control experiment using Rh $\left(\mathrm{NO}_{3}\right)_{3}$ was done (entry 3 in Table 1); the turn-over-rate (TOR) of the homogenous catalyst, $\mathrm{Rh}\left(\mathrm{NO}_{3}\right)_{3}$ without a promoter is only $6.3 \times 10^{-6}$ molecules per rhodium cation per second at $150{ }^{\circ} \mathrm{C}$. Here, the $\mathrm{Rh}_{1} \mathrm{O}_{5} @ Z \mathrm{ZSM}-5$ catalyzes the oxidation of $\mathrm{CH}_{4}$ and $\mathrm{CO}$ with a low-cost oxidant, molecular oxygen or even air at $150{ }^{\circ} \mathrm{C}$ at a solid-liquid-gas interface. TOR of the catalytic sites $\mathrm{Rh}_{1} \mathrm{O}_{5}$ anchored in microporous silicate reaches $0.070 \mathrm{CH}_{3} \mathrm{COOH}$ molecules on per $\mathrm{Rh}_{1} \mathrm{O}_{5}$ site per second in mixture of 50 bar $\mathrm{CH}_{4}$, 10 bar $\mathrm{CO}$, and 8 bar $\mathrm{O}_{2}$ (entry 2 of Table 1). These TORs for production of acetic acid on singly dispersed site $\mathrm{Rh}_{1} \mathrm{O}_{5}$ are much higher than those reported homogenous catalysts ${ }^{32,33}$ by $>1000$ times. As shown in Fig. 2, $840 \mu \mathrm{mol}$ of acetic acid, $352 \mu \mathrm{mol}$ of formic acid, and $82 \mu \mathrm{mol}$ of methanol were produced from $28 \mathrm{mg}$ $0.10 \mathrm{wt} \% \mathrm{Rh} / \mathrm{ZSM}-5$ at $150^{\circ} \mathrm{C}$ for $12 \mathrm{~h}$ under a catalytic condition of 50 bar $\mathrm{CH}_{4}, 10$ bar $\mathrm{CO}$ and 8 bar $\mathrm{O}_{2}$, which correspond to conversion of $10.2 \%$ of $\mathrm{CH}_{4}$ under this condition. Selectivity for production of acetic acid among all organic products reaches about $70 \%$ under this condition. Other than the highest catalytic efficiency on $\mathrm{Rh}_{1} \mathrm{O}_{5} @ Z S M-5$, a significant advantage of our catalytic process is the ready separation of liquid products from the solid catalyst and solvent.

It is found that a shorter reaction time gives a higher selectivity for formation of formic acid and a longer reaction time lead to a higher selectivity for formation of acetic acid. As shown in Supplementary Fig. 9 both formic acid and acetic acid are the main products when reaction time is shorter than $3 \mathrm{~h}$. When the reaction time is $3 \mathrm{~h}$ or longer, acetic acid is the main product. The evolution of the yields of formic acid and acetic acid as a function of time implies that the relative low temperature of catalyst in the heating from 25 to $150{ }^{\circ} \mathrm{C}$ is favorable for the formation of formic acid. More discussion on time-dependent selectivity for formation of formic acid and acetic acid can be found from Supplementary Discussion.

Understanding reaction mechanism at molecular level. Based on the coordination environment of $\mathrm{Rh}_{1}$ atoms suggested by EXAFS studies, we used a structural model whose $\mathrm{Rh}$ atom bonds with three oxygen atoms of the substrate wall and two oxygen atoms of one oxygen molecule in our computational studies. Our DFT calculations suggest that the $\mathrm{Rh}$ atom prefers a tenmembered-ring channel, which has smaller repulsion, instead of a six-membered ring channel of ZSM-5. Based on the experimental preparation method, we expect that the $R h_{1}$ cations replace the Bronsted sites and thus bind to the $\mathrm{Al}$ atoms. As shown in Fig. 6a this $\mathrm{Rh}_{1}$ atom binds to three oxygen atoms of the $\mathrm{Si}-\mathrm{O}$ framework and two oxygen atoms of reactant, making $\mathrm{Rh}_{1}$ exhibit positive to $0.927|\mathrm{e}|$.

Isotope experiments suggest two necessary steps: activation of $\mathrm{C}-\mathrm{H}$ bond of $\mathrm{CH}_{4}$ to form $\mathrm{CH}_{3}$ and insertion of $\mathrm{CO}$ to form 

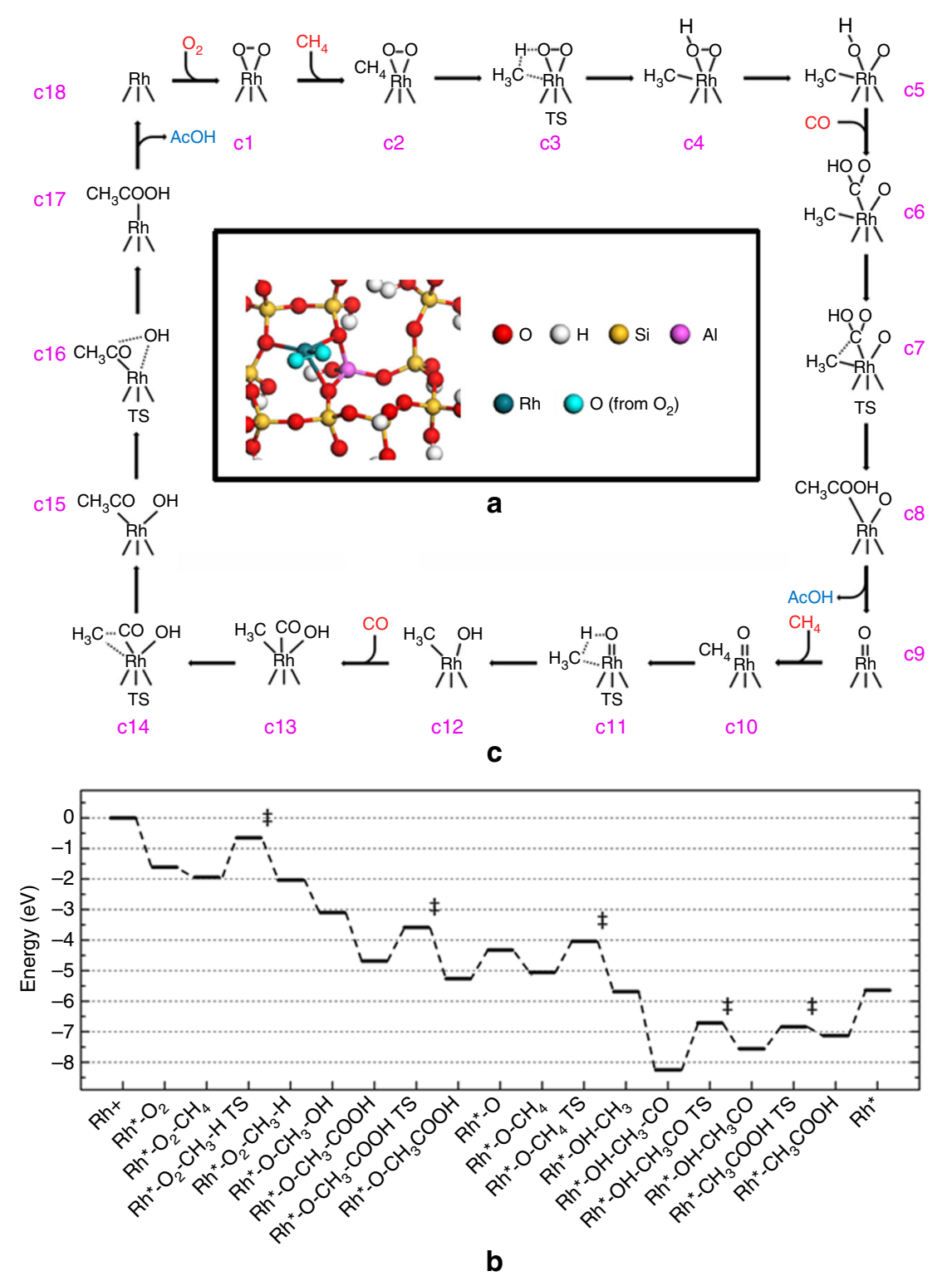

Fig. 6 Computational studies of reaction pathway. Minimum-energy paths and reaction schematic for formation of acetic acid from $\mathrm{CH}_{4}, \mathrm{CO}$, and $\mathrm{O}_{2}$ on $\mathrm{Rh}_{1} \mathrm{O}_{5} / \mathrm{ZSM}-5$. The formation of acetic acid is illustrated in a catalytic cycle starting with the singly dispersed $\mathrm{Rh}_{1} \mathrm{O}_{5}$ site. The balanced reaction cycle consumes one $\mathrm{O}_{2}$, two $\mathrm{CH}_{4}$, and two $\mathrm{CO}$ to make two $\mathrm{CH}_{3} \mathrm{COOH}$ molecules $\left(2 \mathrm{CH}_{4}+2 \mathrm{CO}+\mathrm{O}_{2}=2 \mathrm{CH}_{3} \mathrm{COOH}\right)$. a The optimized catalytic sites, Rh $\mathrm{O}_{5}$ anchored on Brønsted site in microspore of ZSM-5. b Energy profile for pathway of transforming $\mathrm{CH}_{4}, \mathrm{CO}$, and $\mathrm{O}_{2}$ to $\mathrm{CH}_{3} \mathrm{COOH}$. c Intermediates and transition states for a complete catalytic cycle, starting with $\mathrm{Rh}_{1} \mathrm{O}_{5}(\mathrm{c} 1)$. Transition states are highlighted with the double dagger symbols

acetic acid. Based on these experimental findings, reaction pathway on the $\mathrm{Rh}_{1} \mathrm{O}_{5}$ with lowest energy was simulated and transition states were located (Fig. 6). The energy profile and catalytic cycle are illustrated in Fig. $6 \mathrm{~b}, \mathrm{c}$, respectively. The specific energies are listed in Supplementary Table 3. We found that the $\mathrm{Rh}_{1} \mathrm{O}_{5}$ active site (Fig. 6a) participates in the reaction by first activating $\mathrm{C}-\mathrm{H}$ bond of methane (c2 and c3) with an activation barrier of $1.29 \mathrm{eV}$. It forms a methyl and hydroxyl adsorbed on the $\mathrm{Rh}$ atom (c4). Then, a CO molecule can insert to the $\mathrm{Rh}-\mathrm{O}$ bond of $\mathrm{Rh}-\mathrm{O}-\mathrm{H}$, forming a $\mathrm{COOH}$ adsorbed on $\mathrm{Rh}$ (c6). Then $\mathrm{COOH}$ can couple with the adsorbed methyl with a barrier of $1.11 \mathrm{eV}(\mathrm{c} 7)$, forming a weakly adsorbed acetic acid (c8). Subsequent desorption yields the first $\mathrm{CH}_{3} \mathrm{COOH}$ molecule. The remaining Rh-O oxo group (c9) activates $\mathrm{C}-\mathrm{H}$ bond of the second $\mathrm{CH}_{4}$ molecule to form a methyl and a hydroxyl group adsorbed on the $\mathrm{Rh}$ atom (c12). Following, or concurrently to this step, the second $\mathrm{CO}$ molecule binds to the unsaturated $\mathrm{Rh}$ site (c13). Then, the adsorbed CO inserts into the methyl-Rh bond with a barrier of $1.54 \mathrm{eV}$ (c14), forming an acetyl group (c15). Finally, the hydroxyl group couples with carbon atom of $\mathrm{C}=\mathrm{O}$ of the acetyl group to form the second acetic acid with a barrier of $0.72 \mathrm{eV}$ (c17). Desorption of the second acetic acid molecule recovers the $\mathrm{Rh}$ site (c18), which then bonds with a molecular $\mathrm{O}_{2}$, forming a $\mathrm{Rh}_{1} \mathrm{O}_{5}$ site (c1) ready for next catalytic cycle.

Our experimental studies show that high pressure of $\mathrm{CO}$ (Fig. 3b) in fact decreased the activity for producing acetic acid and finally poisoned the active sites. Computational study explored the observed influence of $\mathrm{CO}$ pressure on the catalytic activity. It suggests that saturated coordination of Rh with $\mathrm{CO}$ molecules under $\mathrm{CO}$ gas at a high pressure can poison a $\mathrm{Rh}_{1}$ site and thus prevent it from forming acetic acid. In addition, the DFT calculations show the activation energy for $\mathrm{C}-\mathrm{H}$ of $\mathrm{CH}_{4}$ is largely increased if the $\mathrm{Rh}_{1}$ pre-adsorbed two $\mathrm{CO}$ molecules at high- 
pressure of CO (Supplementary Fig. 10b). More information can be found in Supplementary Discussion.

In summary, the heterogeneous catalyst, $0.10 \mathrm{wt} \% \mathrm{Rh} / \mathrm{ZSM}-5$ consisting of singly dispersed $\mathrm{Rh}_{1} \mathrm{O}_{5}$ sites anchored in the micropores of microporous aluminate silicate was prepared. The anchored $\mathrm{Rh}_{1} \mathrm{O}_{5}$ sites exhibit unprecedented catalytic activity in synthesis of acetic acid higher than free $\mathrm{Rh}^{3+}$ in aqueous solution by $>1000$ times under mild conditions. This heterogeneous catalytic process opens a new route to synthesize acetic acid through direct utilization of methane under a mild condition at $150{ }^{\circ} \mathrm{C}$ or lower by using a low-cost oxidant, $\mathrm{O}_{2}$ or air instead of current industrial process of synthesizing acetic acid through carbonylation of methanol.

\section{Methods}

Preparation and characterization of catalyst. Two steps were involved in the preparation of a $\mathrm{Rh} / \mathrm{ZSM}-5$ catalyst. The first step is the preparation of H-ZSM-5 by calcining zeolite $\mathrm{NH}_{4}-\mathrm{ZSM}-5$ with a $\mathrm{SiO}_{2} / \mathrm{Al}_{2} \mathrm{O}_{3}$ ratio of 23 (Alfa Aesar) in air at $400{ }^{\circ} \mathrm{C}$ for $12 \mathrm{~h}$. Four Rh/ZSM- 5 catalysts with different Rh concentrations $(0.01 \mathrm{wt}$ $\%, 0.05 \mathrm{wt} \%, 0.10 \mathrm{wt} \%, 0.50 \mathrm{wt} \%)$ were synthesized through a method integrating vacuum pumping and IWI of aqueous solution containing certain amount of rhodium(III) nitrate hydrate ( $\sim 36 \% \mathrm{Rh}$ basis, Sigma-Aldrich) at room temperature. Typically, $500 \mathrm{mg}$ of H-ZSM- 5 was placed in a $50 \mathrm{~mL}$ three-port flask. The three ports were sealed with three corks. One port was connected to a vacuum pump. Before injection of $\mathrm{Rh}\left(\mathrm{NO}_{3}\right)_{3}$ solution, air in the flask containing $100 \mathrm{mg} \mathrm{H}-\mathrm{ZSM}-5$ was purged for $3-5 \mathrm{~h}$ by a vacuum pump when the H-ZSM-5 powder was being stirred. The size of stirring bar is $5 \mathrm{~mm}$ for maximizing the amount of H-ZSM-5 to be stirred. Then, $0.30 \mathrm{~mL}$ of $1.0 \mathrm{mg} / \mathrm{mL} \mathrm{Rh}\left(\mathrm{NO}_{3}\right)_{3}$ aqueous solution was added to the H-ZSM-5, which had been pumped for $3-5 \mathrm{~h}$. The injection needle quickly reached the powder to avoid the dispersion of solution to the wall of flask since the environment of flask is in vacuum. In addition, the tip of needle was buried in the middle of H-ZSM-5 powder during injection, minimizing diffusion of solution to the wall of flask. During the injection, the H-ZSM-5 should be continuously stirred.

After the introduction of $\mathrm{Rh}^{3+}$, the samples were further dried in an oven at $80{ }^{\circ} \mathrm{C}$ for $3 \mathrm{~h}$ and calcined in air at $550{ }^{\circ} \mathrm{C}$ for $3 \mathrm{~h}$. Supplementary Fig. 1 schematically shows the evolution of the structure of the anchored Rh atoms in $\mathrm{ZSM}-5$ of $0.10 \mathrm{wt} \% \mathrm{Rh} / \mathrm{ZSM}-5$. Actual Rh contents were determined by inductively coupled plasma atomic emission spectrometry (ICP-AES). TEM (FEI, Titan $80-300$ ) was used to characterize the morphology of the catalyst. EXAFS of Rh Kedge was taken at SPring-8. For EXASF studies, the used catalyst of $0.10 \mathrm{wt} \% \mathrm{Rh} /$ ZSM-5 was measured when the catalyst was kept at $150^{\circ} \mathrm{C}$ in the flow of pure He. The adsorption fine structure spectra of Rh K-edge were fitted using IFEFFIT package and FEFF6 theory. Reference samples including $\mathrm{Rh}$ metal foil and $\mathrm{Rh}_{2} \mathrm{O}_{3}$ nanoparticles supported on $\mathrm{Al}_{2} \mathrm{O}_{3}$ were studied with EXAFS. Their r-space spectra of these reference samples were fitted with the same software. XPS was performed using a PHI5000 VersaProbe Spectrometer with monochromated Al Ka as X-ray source.

Catalytic reactions. Transformation of methane to acetic acid on $0.10 \mathrm{wt} \% \mathrm{Rh} /$ ZSM-5 was performed in a Parr high-pressure reactor (Series 4790, Parr) containing a Teflon liner vessel (Supplementary Fig. 3b). 28 milligram $0.10 \mathrm{wt} \% \mathrm{Rh} /$ ZSM-5 was added to $10 \mathrm{~mL} \mathrm{H}_{2} \mathrm{O}$ in the reactor. After evacuating the air left in reactor by flowing $\mathrm{CH}_{4}(99.9 \%$, Matheson) and purging for five times, the system was pressurized with reactant gases in a sequence of $\mathrm{CH}_{4}, \mathrm{CO}(99.9 \%$, Matheson) and $\mathrm{O}_{2}(99.9 \%$, Matheson) to their desired pressures. The high-pressure reactor was completely sealed and then heated to the desired reaction temperature (typically $150^{\circ} \mathrm{C}$ ) by placing it in an oil bath. The temperature controller of the heating plate (VWR International) was used to measure the temperature of solution in the Parr reactor through the thermocouple placed in solution of Parr reactor and to control the temperature through outputting tunable power to the heating plate. Once the desired catalysis temperature was reached, the solution was vigorously stirred at $1200 \mathrm{rpm}$ and was maintained at the reaction temperature for certain amount of time. After completion of the reaction, the vessel was cooled in an ice bath to a temperature below $10^{\circ} \mathrm{C}$ to minimize the loss of volatile products. The solution with liquid products was filtered from the catalyst powder. The clean liquid containing acetic acid, formic acid, and methanol was analyzed by ${ }^{1} \mathrm{H}-\mathrm{NMR}$ or ${ }^{13} \mathrm{C}$-NMR. The concentration of $\mathrm{Rh}$ in the filtered powder was examined with ICP-AES as described in Supplementary Methods. Supplementary Fig. 11 is the standard curve of ICP-AES studies of Rh concentrations.

Measurements of products with NMR and GC. ${ }^{1} \mathrm{H}$ NMR spectra were collected at room temperature on a Bruker AVANCE III HD 400 spectrometer at University of Notre Dame and University of Kansas. The measurements were calibrated by using 3-(trimethylsilyl)-1-propanesulfonic acid sodium salt (DSS) residual signal at $\delta=0.0 \mathrm{ppm}$. Supplementary Fig. 4 is a typically NMR spectrum of products formed from $\mathrm{CH}_{4}$ transformation. Obviously, the peak of DSS can be identified.
Typically, $0.7 \mathrm{~mL}$ collected filtrate and $0.1 \mathrm{~mL}$ of $\mathrm{D}_{2} \mathrm{O}$ (with $0.02 \mathrm{wt} \% \mathrm{DSS}$ ) were mixed in an NMR tube for analysis. The identified oxygenated products were acetic acid $(\delta=2.08 \mathrm{ppm})$, formic acid $(\delta=8.24 \mathrm{ppm})$ and methanol $(\delta=3.34 \mathrm{ppm})$. A solvent suppression program was applied in order to minimize the signal originating from $\mathrm{H}_{2} \mathrm{O}$, similar to our previous studies ${ }^{11}$. To quantify the products, standard curves were built using the same method as that of our previous report ${ }^{11}$ To establish a standard curve of a specific product such as acetic acid, a series of standard solutions with different concentrations of acetic acid were prepared. For instance, to establish a standard curve acetic acid, a series of standard solutions with different concentrations of acetic acid were prepared. NMR spectra of these standard solutions were collected with the exactly same parameters of NMR measurements. The ratio of the area of peak of acetic acid $(\delta=2.08 \mathrm{ppm})$ to area of DSS of the same solution were calculated. These ratios of solutions with different concentrations of acetic acid were plotted as a function of the concentrations of acetic acid. This graph is a standard curve of acetic acid (Supplementary Fig. 5a), formic acid (Supplementary Fig. 5b), and methanol (Supplementary Fig. 5c). Concentration of a product (such as acetic acid) in a solution after catalysis in Parr reactor was determined by locating the ratio of the peak area of the product to the area of DSS on the $y$-axis of the standard curve (such as Supplementary Fig. 5a) and then finding the corresponding value on $x$-axis, which is the amount of the product of the solution after a catalysis in the unit of $\mu \mathrm{mol}$. Gases in the head of Parr reactor after catalysis were analyzed with GC. Supplementary Table 4 presents the amounts of all reactants before catalysis and all products and left reactants after the catalysis: this catalysis was performed on $28 \mathrm{mg} 0.10 \mathrm{wt} \% \mathrm{Rh} / \mathrm{ZSM}-5$ dispersed in $10 \mathrm{~mL}$ deionized $\mathrm{H}_{2} \mathrm{O}$ under 50 bar $\mathrm{CH}_{4}, 10$ bar $\mathrm{CO}$, and 8 bar $\mathrm{O}_{2}$ for $3 \mathrm{~h}$. Bruker Topspin 3.5 software was used to acquire, process, and visualize the data.

Data availability. All data are available from the authors upon reasonable request

Received: 17 September 2016 Accepted: 19 January 2018

Published online: 26 March 2018

\section{References}

1. Mattos, L. V., Jacobs, G., Davis, B. H. \& Noronha, F. B. Production of hydrogen from ethanol: Review of reaction mechanism and catalyst deactivation. Chem. Rev. 112, 4094-4123 (2012).

2. Liu, Y. et al. Efficient conversion of methane to aromatics by coupling methylation reaction. ACS Catal. 6, 5366-5370 (2016).

3. Ali, A., Alvarez, W., Loughran, C. J. \& Resasco, D. E. State of Pd on H-ZSM-5 and other acidic supports during the selective reduction of NO by CH4 studied by EXAFS/XANES. Appl. Catal. B: Environ. 14, 13-22 (1997).

4. Ali, A., Chin, Y. H. \& Resasco, D. E. Redispersion of Pd on acidic supports and loss of methane combustion activity during the selective reduction of NO by CH4. Catal. Lett. 56, 111-117 (1998).

5. Hammond, C. et al. Direct catalytic conversion of methane to methanol in an aqueous medium by using copper-promoted Fe-ZSM-5. Angew. Chem. Int. Ed. 51, 5129-5133 (2012).

6. Yoshizawa, K., Shiota, Y., Yumura, T. \& Yamabe, T. Direct methane-methanol and benzene-phenol conversions on Fe-ZSM-5 zeolite: Theoretical predictions on the reaction pathways and energetics. J. Phys. Chem. B. 104, 734-740 (2000)

7. Kuroda, Y. et al. On the possibility of AgZSM-5 zeolite being a partial oxidation catalyst for methane. J. Colloid Interface Sci. 333, 294-299 (2009).

8. Mahyuddin, M. H., Staykov, A., Shiota, Y. \& Yoshizawa, K. Direct conversion of methane to methanol by metal-exchanged ZSM-5 zeolite (Metal $=\mathrm{Fe}, \mathrm{Co}$, Ni, Cu). ACS Catal. 6, 8321-8331 (2016).

9. Goltl, F. et al. Computationally exploring confinement effects in the methaneto-methanol conversion over iron-oxo centers in zeolites. ACS Catal. 6, 8404-8409 (2016).

10. Behrens, $\mathrm{M}$. et al. The active site of methanol synthesis over $\mathrm{Cu} / \mathrm{ZnO} / \mathrm{Al} 2 \mathrm{O} 3$ industrial catalysts. Science 336, 893-897 (2012).

11. Huang, W. X. et al. Low-temperature transformation of methane to methanol on Pd1O4 single sites anchored on the internal surface of microporous silicate. Angew. Chem. Int. Ed. 55, 13441-13445 (2016).

12. Coperet, C. et al. Surface organometallic and coordination chemistry toward single-site heterogeneous catalysts: strategies, methods, structures, and activities. Chem. Rev. 116, 323-421 (2016).

13. Pelletier, J. D. A. \& Basset, J. M. Catalysis by design: Well-defined single-site heterogeneous catalysts. Acc. Chem. Res. 49, 664-677 (2016).

14. Serna, P. \& Gates, B. C. Molecular metal catalysts on supports: Organometallic chemistry meets surface science. Acc. Chem. Res. 47, 2612-2620 (2014).

15. Yang, X. F. et al Single-atom catalysts: a new frontier in heterogeneous catalysis. Acc. Chem. Res. 46, 1740-1748 (2013).

16. Zhang, S. R. et al. Catalysis on singly dispersed bimetallic sites. Nat. Commun. 6, 7938 (2015). 
17. Qiao, B. T. et al. Single-atom catalysis of $\mathrm{CO}$ oxidation using Pt-1/FeOx. Nat. Chem. 3, 634-641 (2011).

18. Tao, F. et al. Reaction-driven restructuring of Rh-Pd and Pt-Pd core-shell nanoparticles. Science 322, 932-934 (2008).

19. Mulukutla, R. S., Asakura, K., Namba, S. \& Iwasawa, Y. Nanosized rhodium oxide particles in the MCM-41 mesoporous molecular sieve. Chem. Comm. 0, 1425-1426 (1998).

20. Mulukutla, R. S., Shido, T., Asakura, K., Kogure, T. \& Iwasawa, Y. Characterization of rhodium oxide nanoparticles in MCM-41 and their catalytic performances for NO-CO reactions in excess O2. Appl. Catal. A: Gen. 228, 305-314 (2002).

21. Dent, A. J. et al. Rhodium dispersion during NO/CO conversions. Angew. Chem. Int. Ed. 46, 5356-5358 (2007)

22. Martinez-Macias, C., Serna, P. \& Gates, B. C lsostructural zeolite-supported rhodium and iridium complexes: Tuning catalytic activity and selectivity by ligand modification. ACS Catal. 5, 5647-5656 (2015).

23. Serna, P. \& Gates, B. C. Zeolite-supported rhodium complexes and clusters: Switching catalytic selectivity by controlling structures of essentially molecular species. J. Am. Chem. Soc. 133, 4714-4717 (2011).

24. Liang, A. J. et al. A site-isolated rhodium-diethylene complex supported on highly dealuminated Y zeolite: Synthesis and characterization. J. Phys. Chem. B. 109, 24236-24243 (2005).

25. Yang, D., Xu, P. H., Browning, N. D. \& Gates, B. C. Tracking Rh atoms in zeolite HY: First steps of metal cluster formation and influence of metal nuclearity on catalysis of ethylene hydrogenation and ethylene dimerization. $J$. Phys. Chem. Lett. 7, 2537-2543 (2016).

26. $\mathrm{Wu}, \mathrm{J}$. F. et al. Mechanistic insight into the formation of acetic acid from the direct conversion of methane and carbon dioxide on zinc-modified H-ZSM-5 zeolite. J. Am. Chem. Soc. 135, 13567-13573 (2013).

27. Yu, Z. W. et al. Bronsted/Lewis acid synergy in H-ZSM-5 and H-MOR zeolites studied by $\mathrm{H}-1$ and Al-27 DQ-MAS solid-state NMR spectroscopy. J. Phys. Chem. C. 115, 22320-22327 (2011).

28. Shan, J. J. et al. Conversion of methane to methanol with a Bent Mono(muoxo)dinickel anchored on the internal surfaces of micropores. Langmuir 30, 8558-8569 (2014).

29. Budiman, A. W. et al. Review of acetic acid synthesis from various feedstocks through different catalytic processes. Catal. Surv. Asia 20, 173-193 (2016).

30. Kinnunen, T. \& Laasonen, K. The oxidative addition and migratory 1,1insertion in the Monsanto and Cativa processes. A density functional study of the catalytic carbonylation of methanol. J. Mol. Struc. Theochem. 542, 273-288 (2001).

31. Maitlis, P. M., Haynes, A., Sunley, G. J. \& Howard, M. J. Methanol carbonylation revisited: Thirty years on. J. Chem. Soc., Dalton Trans. 0 2187-2196 (1996).

32. Lin, M. \& Sen, A. Direct catalytic conversion of methane to acetic acid in an aqueous-medium. Nature 368, 613-615 (1994).

33. Periana, R. A., Mironov, O., Taube, D., Bhalla, G. \& Jones, C. J. Catalytic, oxidative condensation of $\mathrm{CH} 4$ to $\mathrm{CH} 3 \mathrm{COOH}$ in one step via $\mathrm{CH}$ activation. Science 301, 814-818 (2003).
34. Zerella, M., Mukhopadhyay, S. \& Bell, A. T. Direct oxidation of methane to acetic acid catalyzed by $\mathrm{Pd} 2+$ and $\mathrm{Cu} 2+$ in the presence of molecular oxygen. Chem. Comm. 0, 1948-1949 (2004).

\section{Acknowledgements}

This work was solely supported by the U.S. Department of Energy, Office of Science, Office of Basic Energy Sciences, Chemical Sciences, Geosciences, and Biosciences Division under Award Number DE-SC0014561 of Catalysis Science Program. Y.L. and F.T. appreciated J. Douglas of NMR lab of KU for valuable discussion in solid-state NMR data measurements. J. Shan learnt sample preparation and catalysis studies of this work in the years 2013 and 2014 when being trained for studies of catalysis in liquid. A.I.F. is partially supported by the U.S. DOE Grant No. DE-FG02-03ER15476.

\section{Author contributions}

Y.T., Y. L. and V.F. equally contributed to this work. F.T. developed the concept, designed these experiments, analyzed experimental data, and wrote the paper. W.H, S.Z., Y.T., Y.L., L.N. and X.Z. performed catalyst preparation and catalytic measurements and analysis of data. Y.F. and D.J. developed computational studies. Y. T., Y.I., T.S., and A.I.F. collected and analyzed XAS data. All authors discussed the results and commented on the manuscript.

\section{Additional information}

Supplementary Information accompanies this paper at https://doi.org/10.1038/s41467018-03235-7.

Competing interests: The authors declare no competing financial interests.

Reprints and permission information is available online at http://npg.nature.com/ reprintsandpermissions/

Publisher's note: Springer Nature remains neutral with regard to jurisdictional claims in published maps and institutional affiliations.

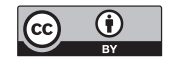

Open Access This article is licensed under a Creative Commons Attribution 4.0 International License, which permits use, sharing, adaptation, distribution and reproduction in any medium or format, as long as you give appropriate credit to the original author(s) and the source, provide a link to the Creative Commons license, and indicate if changes were made. The images or other third party material in this article are included in the article's Creative Commons license, unless indicated otherwise in a credit line to the material. If material is not included in the article's Creative Commons license and your intended use is not permitted by statutory regulation or exceeds the permitted use, you will need to obtain permission directly from the copyright holder. To view a copy of this license, visit http://creativecommons.org/ licenses/by/4.0/.

(C) The Author(s) 2018 